Portland State University

PDXScholar

Dissertations and Theses

Dissertations and Theses

Summer 7-26-2018

\title{
White Space, Black Space: Community Gardens in Portland, Oregon
}

David Ross Billings Jr.

Portland State University

Follow this and additional works at: https://pdxscholar.library.pdx.edu/open_access_etds

Part of the Sociology Commons

Let us know how access to this document benefits you.

Recommended Citation

Billings Jr., David Ross, "White Space, Black Space: Community Gardens in Portland, Oregon" (2018). Dissertations and Theses. Paper 4550.

https://doi.org/10.15760/etd.6435

This Thesis is brought to you for free and open access. It has been accepted for inclusion in Dissertations and Theses by an authorized administrator of PDXScholar. Please contact us if we can make this document more accessible: pdxscholar@pdx.edu. 
White Space, Black Space:

Community Gardens in Portland, Oregon

by
David Ross Billings Jr.

\section{David Ross Billings Jr.}

A thesis submitted in partial fulfillment of the requirements for the degree of

Master of Science

in Sociology

Thesis Committee:

Julius McGee, Chair

Amy Lubitow

Nathan McClintock

Portland State University

2018 
(C) 2018 David Ross Billings Jr. 


\begin{abstract}
Community gardens have been the focus of social science research in the United States for several decades and the benefits associated with these alternative food spaces has been well documented. More recently, scholars have begun to argue that these benefits are inequitably distributed across society. Largely as a result of the whiteness of these spaces, people of color are less represented in community and benefit less from their presence. Portland, Oregon is recognized as a leader in sustainability, with its abundance of community gardens and urban agriculture. It is also one of the whitest urban cities in the United States. People of color have faced a legacy of oppression and marginalization in Portland, and this is especially true for the black community. Through conducting 17 indepth interviews and spending an extensive amount of time observing community gardens in Portland, this research aims to explore how the whiteness of these spaces functions to marginalize black individuals and contributes to the ongoing oppression of the black community. This research also demonstrates how the black community in Portland engages community gardening in an effort to resist these and broader effects of structural racism.
\end{abstract}




\section{ACKNOWLEDGMENTS}

I am truly grateful to my advisor, Doctor Julius McGee. This research would not have been possible without his patience, guidance, and assistance. Additionally, I would like to express my gratitude to my partner and to my family for all of their support and encouragement throughout this project. Most importantly, I would like to thank all of the black community gardeners who shared their time and lives’ experiences for this study. 
TABLE OF CONTENTS

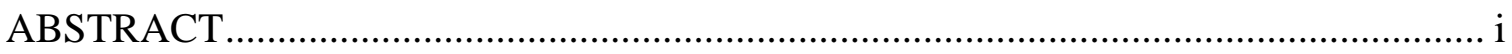

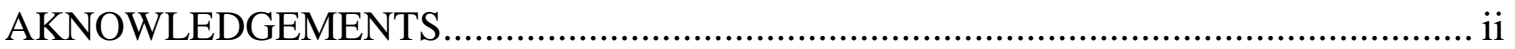

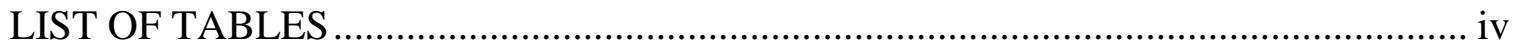

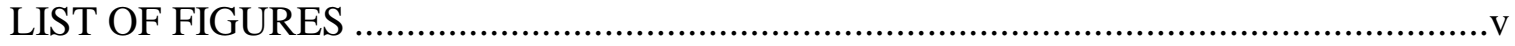

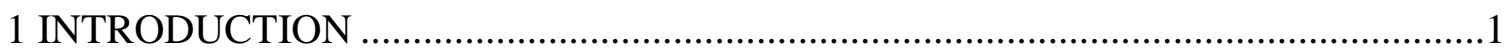

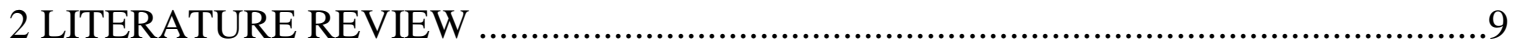

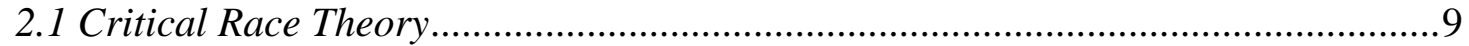

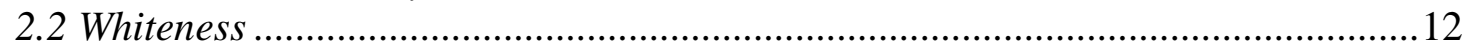

2.3 Community Gardens in the United States...........................................................18

2.4 Portland, Oregon ...........................................................................................29

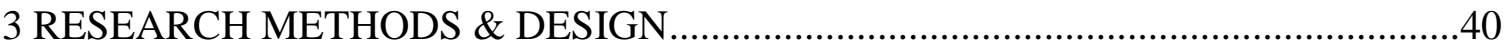

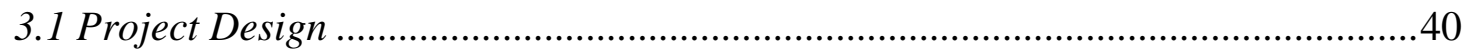

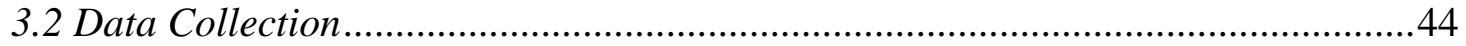

3.3 Data Analysis .............................................................................................48

3.4 Advantages and Limitations...........................................................................49

4 FINDINGS: Whiteness and Portland's Community Gardens ..........................................51

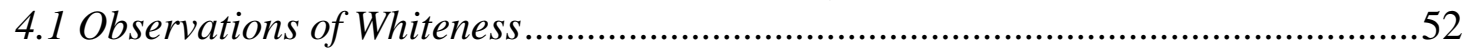

4.2 Experiences of Black Gardeners.......................................................................5

5 FINDINGS: Black Gardeners and Black Garden Spaces ................................................73

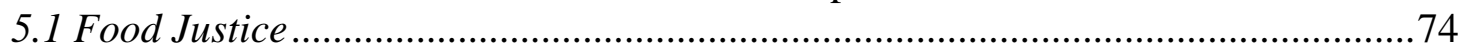

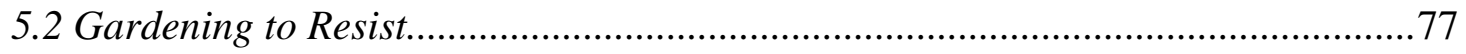

5.3 Reflections, Leadership, and Identity.................................................................81

6 CONCLUSION

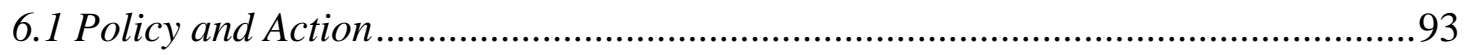

6.2 Limitations and Future Research..........................................................................95

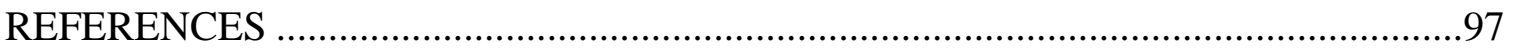

APPENDIX A: Interview Guide...............................................................................104

APPENDIX B: Human Subjects Approval..................................................................105 
LIST OF TABLES

Table 1: Race/Ethnicity for PPR Community Garden Plot-holders (2016) Compared to

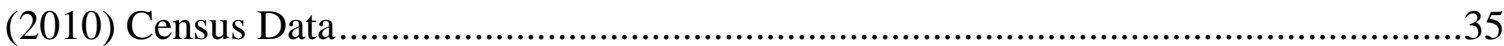

Table 2: Research Sites, Participants, Observation, and Racial Coding...........................45

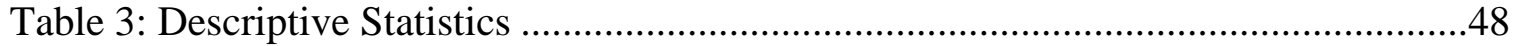


LIST OF FIGURES

Figure 1: Portland Parks and Recreation Gardener Reminder Chart..............................37

Figure 2: Map of Research Sites ........................................................................45 


\section{INTRODUCTION}

Community gardens have existed in the United States for over a century and have proliferated in many urban cities in the past few decades. They have been recognized as an effective tool for addressing hunger and food security and they been associated with a wide range of other benefits as well. In a review of research on community gardens, Draper and Freedman (2010) found that improved health, food security, economic development, preservation of open space, crime prevention, neighborhood improvement, cultural preservation or expression, social interaction, and community organizing and empowerment were among some of the many benefits regularly associated with community gardens. Some researchers have also claimed that community gardens are sites of interracial interaction (Shinew, Glover, and Parry 2004) and cultural expression (Saldivar-Tanaka and Krasny 2004). However, a more critical body of literature asserts that the benefits associated with community gardens are inequitably distributed in many places. Some researchers have claimed that community gardens, along with farmers markets and other types of alternative food networks, are often white spaces (Slocum 2006; Hoover 2013) that serve to benefit white individuals, regularly at the expense and exclusion of people of color (Guthman 2008; Pilgeram 2012).

Portland, Oregon is known for being an urban hub for community gardens and a leader in sustainability, and scholars have recently began to study sustainability here (Mendes et al 2008; Goodling et al. 2015; McClintock, Miewald, and McCann 2018). Some of this research has indicated that the benefits associated with sustainability are inequitably distributed in Oregon’s largest city (Gooding, Green, and McClintock 2015). 
Other research has claimed that community gardens in Portland are generally viewed as spaces to grow food and build community but not as tools for critiquing larger structural concerns that are linked to the food system, as is the case for food justice oriented community gardens (McClintock et al. 2018). In a recent study of one of the city’s community garden organizations, Zinschlag (2014) warned that unjust sustainability in Portland might be the result of not just a lack of concern for inequality, but also a basic lack of awareness of it. Inequality is not a new problem for the Rose City, though. The state of Oregon, and Portland more specifically, has had a long history of racism and oppression of people of color, much of which has been targeted at the black community (Gibson 2007; Bates Curry-Stevens, and CCC 2014; Burke and Jeffries 2016). Despite these more recent criticisms, the City’s community gardens continue to be a major feature attributed to its overall sustainability and livability.

In an effort to contribute to these ongoing discussions within the literature, this research explores the question: what are the experiences of black community gardeners in Portland, Oregon? Through the lens of Critical Race Theory (Delgado and Stefancic 2017), this research aims to explore these experiences in order to better understand the racial dynamics of these spaces, and how those dynamics may influence the distribution of the benefits commonly associated with them. Critical Race Theory (CRT) acknowledges the centrality of race and racism in the lived experiences of people of color, and encourages the dissemination of this experiential knowledge through the sharing of their stories. Nested within this theoretical framework is the concept of whiteness, which I elaborate on using a transdisciplinary perspective, one of the central tenets of the CRT framework (Solorzano, Ceja, and Yosso 2000). 
Drawing on literature from the fields of Legal Studies (Delgado and Stefancic 1997, 2017), Sociology (Du Bois 1995; Doane 2003; Guthman 2008; Bonilla-Silva 2015; Alkon and Guthman 2017), Geography (Pulido 2000; Kobayashi and Peake 2000; Andersen 2003), Philosophy (Gooding-Williams and Mills 2014; Yancy 2017) and Anthropology (Slocum 2006, 2007), this research provides a robust elaboration of the concept of whiteness. I employ whiteness as a conceptual tool to explore the various manifestations of contemporary whiteness, the ideologies that reinforce it, and the way whiteness is connected to privilege and to the oppression of people of color. Based on the previous literature and my initial knowledge of community gardens in Portland, I developed the following research questions: (1) how do black individuals experience community gardens in Portland, Oregon as racialized spaces? (2) How are black gardeners’ practices and participation in urban agriculture in Portland influenced by racism and whiteness? (3) In what ways do the features of a community garden influence black individuals’ participation in Portland?

The concept of whiteness has been used in previous criticisms of alternative food (Slocum 2006, 2007; Guthman 2008; Pilgeram 2012; Henson 2014; Alkon and Vang 2016) and several gaps within this critical body of literature have been highlighted, including the need for the inclusion of the experiences and perspectives of people of color in this research (Guthman 2008; Hoover 2013). This study aims to address this specific gap by exploring the way the whiteness of these spaces influences black community gardeners. Portland's status as the whitest metropolitan city in the US (Renn 2009 as cited by Hern 2016) makes it an ideal place to study this phenomenon. This research also aims to add to the literature on food justice, by showing how these white community 
gardens contrast black garden spaces, in the way they benefit and impact marginalized communities. While black garden spaces regularly focus on food justice and benefitting marginalized communities, white community gardens are often associated with oppressive processes, including exclusion and displacement. This study also adds to the literature on food justice by demonstrating the barriers to the creation of black garden spaces, including the effects of institutional oppression and white resistance, which are both founded in colorblind ideology (Bonilla-Silva 2015) and post-racialist beliefs (Gooding-Williams and Mills 2014).

In total, I conducted 17 semi-structured, in depth interviews with black community gardeners in Portland. As outsiders within (Collins 1986) the mostly white city of Portland, and the mostly white alternative food spaces of community gardens, these individuals were asked about their experiences in the gardens, perceptions of that space and of other gardeners, and also about the impact these factors had on their participation and their experience overall. Participants were also asked to discuss their motivations for gardening and how gardening benefitted them. As a means of triangulation (Creswell \& Miller 2000), I spent approximately 60 hours of observation at 10 separate community gardens (2 black garden spaces, 7 white gardens, and one that did not fit either description), had conversations with the current program director of the Portland Parks and Recreation (PPR) community garden program, and reviewed grant documents from some of PPR's gardens. This information provided me with a nuanced understanding of Portland's community gardens as well as insights into the structure and ideologies of PPR community garden program specifically. I took field notes following 
each interview, as well as during periods of observation at the gardens, and included some of my own observations and experiences from this project.

In the following chapter, I begin with a review of the literature. First I examine the primary theories and concepts used in this study, and then explore the previous research on community gardens and the way these theories and concepts have been previously applied in the literature on community gardens and on alternative food more broadly. Next I discuss what I will refer to as black food spaces, which have been discussed in previous research (Alkon and Agyeman 2011; Sbicca 2012; Ramirez 2014; Figueroa and Alkon 2017) using different labels. These spaces are often centered on notions of food justice and food sovereignty, which are much less commonly addressed in white community gardens. I also include a discussion of historical trauma, and the way it is connected to agriculture in the US, both as a deterrent and source of motivation for many black individuals (Finney 2014; Reynolds and Cohen 2016; Alkon and Guthman 2017). Next, I explore the Racial Formation (Omi and Winant 2015) of Portland, specifically focusing on the history of oppression of the black community in Portland, and I illustrate the ways previous development efforts have been used to benefit white residents within the city at the expense of the black community. The final section of the literature review includes an introduction of Portland's community gardens, and discusses both white gardens and black garden spaces. Finally, the literature review concludes with the statement of my specific research questions, which were informed by previous empirical and theoretical work highlighted in the review.

Following the literature review I explain the methods used in this research and the specific epistemological motivations for limiting the participants of this study to black 
Portlanders. Specifically, I employ the Outsider within Epistemology (Collins 1986), which compliments the notion of a voice of color within CRT (Delgado and Stefancic 2017). The notion of the outsider within highlights the way in which people of color are more able to see oppression and racism within society, and how an outsider status in a specific space or setting may enhance this phenomenon. I briefly review the history of this epistemology and list some of its previous applications in previous research, before demonstrating how I intend to incorporate it into my own study. By interviewing black individuals in a predominantly white city who participate in a movement that has been criticized for being largely white, I was able to access some of this experiential knowledge and explore it using the theories and concepts described above. I also used observation at several community gardens, conversations with PPR's community garden directors (both past and present), and reviewed archived PPR documents as additional sources of information and as a means of triangulation.

After introducing the methods for this study, I present my findings in two chapters. The first chapter uses a combination of my observations and the experiences of the gardeners I interviewed to highlight the way that community gardens can be perceived and experienced as white spaces. In addition to about 60 hours spent observing at several gardens, my interpretations were shaped by conversations with the current and former director of the PPR's community garden program and by information gathered from archived documents (grant applications, communications about garden development, etc.) at the PPR offices in Portland. The second chapter explores the concerns that motivate most of the gardeners I interviewed, including the pursuit of food justice and a desire to resist oppression and historical trauma. The pursuit of these 
specific motivations was described as being enabled by certain features of a community garden, including the presence of other black gardeners, black leadership, and an emphasis on black identity and culture.

Overall, I find that many black community gardeners in Portland do experience community gardens as white spaces, which limits or deters their participation in these gardens. Black community gardeners' experiences with whiteness extend beyond the physical spaces of individual gardens and several gardeners' experiences with whiteness shaped their understanding of Oregon's food system more broadly. I also find that many black gardeners are motivated by a food justice concerns and the desire to resist oppression and historical trauma. Black garden spaces provide benefits to black individuals that community gardens which are coded as white do not, and in most cases cannot. Many of these benefits are the result of specific attributes, including the presence of other black gardeners, black leadership, and an emphasis on black identity and culture. Additionally, black garden spaces act as counterspaces (Case 2012) for the black community, which are increasingly important because places that previously served this function have been eliminated by gentrification. While the black community seeks to create and sustain spaces such as these, they face barriers through structural oppression and the resistance of white individuals and organizations.

The final chapter of this thesis concludes with a discussion of the research questions and highlights some of the implications of this research. I address the findings overall and then discuss each research question individually. I also make some recommendation for Portland Parks and Recreation and discuss the theoretical benefits of supporting the growth of black garden spaces in Portland. Finally, I conclude by 
discussing some of the major limitations of this research and suggest some directions for future studies of race and community gardens in Portland, Oregon. 


\section{LITERATURE REVIEW}

\subsection{Critical Race Theory}

This research employs Critical Race Theory (Crenshaw 1995; Delgado and Stefancic 2017) as its dominant theoretical framework. Critical Race Theory (CRT) is an interdisciplinary theory that acknowledges that "racism is pervasive, systemic, and deeply ingrained” within the United States (Delgado and Stefancic 2017:91). CRT originated in the late 1970s within legal scholarship, and since then the movement surrounding CRT has expanded to include a wide variety of individuals in activism and academia, who are interested in understanding and ultimately transforming the relationship between race, racism, and power in the US (Delgado and Stefancic 2017). The CRT framework relies on five general components, including “(1) the centrality of race and racism and their intersectionality with other forms of subordination, (2) the challenge to dominant ideology, (3) the commitment to social justice, (4) the centrality of experiential knowledge, and (5) the transdisciplinary perspective” (Solorzano, Ceja, and Yosso 2000:63). CRT also assumes that (1) racism is ordinary in the US and the common experience of people of color; (2) white supremacy benefits all white individuals to some extent, which leaves little motivation to overturn it; (3) race is a social construct (not corresponding to biology or genetics); and (4) unique experiences with oppression give people of color a certain "voice of color" that allows them to produce knowledge about race and racism usually unintelligible to whites (Delgado and Stefancic 2017).

Critical Race Theory has been used to explore the way people of color are systematically oppressed and how this is connected to their relationship with the 
environment. In a study of the racialized relationship between African Americans and the environment, Finney (2014) demonstrated that there is a need to draw on diverse sources of information to explore the intricacies of the relationship and suggested that CRT, in combination with other viewpoints, allows for a framework that is broad and adaptable enough to do so. Finney also used CRT to explore the way that historical racism and conceptions of race have influenced African American participation in environmental movements. In a more micro-level study of the urban environment, Garcia, Gee, and Jones (2016) used CRT to examine disparities in access to parks in Los Angeles. They found that people of color were intentionally excluded from parks and outdoor spaces by city planners, politicians, and white residents, through methods of de facto segregation, zoning laws, and fiscal discrimination. They pointed out how these patterns are important when considering connections between the built environment and racial disparities in health outcomes.

Because community gardens exist within the same structural confines as most other institutions in society, and can be viewed as both a part of the built environment and a type of environmental movement, CRT provides an ideal lens through which to explore the ways racism has been ingrained in within community garden spaces. CRT has been applied sparingly within the literature on community gardens and Urban Agriculture (UA), but the few instances that do exist demonstrate the utility this framework can provide when considering the racial dynamics of community gardens. In a noteworthy publication, Hoover (2013) encouraged researchers to consider UA through the CRT framework to examine white spaces and white privilege that exists in a movement that should be generally aimed at increasing food justice. He also points out a need for future 
research to include the perception of marginalized groups in regards to $\mathrm{UA}$, and how they view themselves engaging in the movement surrounding it.

A study of community gardens in New York City (the US city with largest number of community gardens) was recently conducted by Reynolds, who claimed that "viewed through the lens of CRT, the re-inscription of racial disparities and white privilege within alternative food movements becomes less surprising, and can even be expected without conscious effort to dismantle oppression at numerous levels, from the personal to the structural” (2014:245). Reynolds and Cohen (2016) later elaborated on the application of CRT in the study of UA by examining the influence of structural racism on New York City’s UA and community garden programs. They claimed that, “the cumulative system of racial bias that extends across society and perpetuates disadvantage among communities of color,” is reinforced by internalized racism, interpersonal racism, and institutionalized racism. Further, they argued that "CRT explains that racial inequalities grow from patterns of implicit racial bias--which exist within whole institutions and extend throughout society--not simply from individuals’ explicitly racist beliefs or isolated instances of racial discrimination” (Reynolds and Cohen 2016:10).

By employing CRT in the study of community gardens, I aim to provide another example of the ways this theory can be adapted to various dimensions of US society, and to contribute to the literature which demonstrates how racism is ingrained in the built environment and works to exclude people of color from environmental movements. While CRT provides a useful overall framework for the exploration of racism with community gardens, the specific manifestation of racism with which this research is interested in understanding requires additional conceptual tools. Because community 
gardens have been criticized for being white spaces (Slocum 2006; Hoover 2013), it is necessary to include an exploration of this concept. While Critical Whiteness Studies is a subfield nested within Critical Race Theory, this research will rely on an interdisciplinary understanding of the concept of whiteness. This is necessary because of the multitude of disciplines that have made important contributions to this topic, and because the interdisciplinary study of race is central to CRT (Delgado and Stefancic 2017).

\subsection{Whiteness}

This research will use whiteness as a conceptual tool for exploring the racialized dynamics of the community gardens in Portland, drawing on literature from the fields of Legal Studies (Delgado and Stefancic 1997, 2017), Sociology (Du Bois 1995; Doane 2003; Guthman 2008; Bonilla-Silva 2015; Alkon and Guthman 2017), Geography (Pulido 2000; Kobayashi and Peake 2000; Andersen 2003), Philosophy (GoodingWilliams and Mills 2014; Yancy 2017) and Anthropology (Slocum 2006, 2007). The study of whiteness has become more prevalent in the last two decades, though it is not at all a new phenomenon. As early as 1910, W.E.B. Du Bois was writing about the “discovery of whiteness among the world’s peoples” and in his 1920 publication he lamented that, “Then always, somehow, some way, silently but clearly, I am given to understand that whiteness is the ownership of the earth forever and ever, Amen!” (1995:454). Doane (2003) considers the contemporary study of whiteness to be a “repackaging” of ideas previously articulated regarding whiteness, with an explicit focus on whiteness as the topic of interest. And while the study of whiteness may have been around for some time, the effects of whiteness have been around even longer. Omi and 
Winant note that from its earliest days as a country “Anglo-conformity” helped to make whiteness a lasting norm that continues to influence the nation's culture and appearance (2015:77).

Whiteness is defined in many ways throughout the literature, but there are some common assumptions that are generally agreed upon among the scholars of whiteness. First of all, whiteness is normative, yet malleable. It is normative in the way it is centered in society to control values and institutions, and marginalizes the culture and values of nonwhite groups so that the term American usually connotes images of white individuals (Delgado and Stefancic 1997, 2017; Kobayashi and Peake 2000; Bonilla-Silva 2003; Doane 2003; Guthman 2008; Yancy 2017). Whiteness is malleable in the way it transforms itself over time (Bonilla-Silva 2003; Slocum 2007). Various groups and individuals have been able access whiteness to a certain extent, by adopting and integrating into white culture, or "passing" as white (Pulido 2000). This has been the case historically for ethnic groups such as Irish and Italians, who were not always considered white as they are now, and this may be the case for other ethnic groups in the future (Delgado and Stefancic 1997, 2017; Bonilla-Silva 2003).

Second, whiteness is usually invisible to most white Americans, or at least less visible than it is to individuals from other racial or ethnic groups (Delgado and Stefancic 1997, 2017; Doane 2003). For white individuals, their own race is often transparent so that they do not see it as a main component of their identities' in the way they do for people of color. As a result of this transparency, white individuals do not usually consider their positionality to be based on their race (Slocum 2006). Doane (2003) has suggested that because sociologists have found that many white individuals have not even 
considered the meaning of whiteness, this should be the central component of interest for sociologists studying whiteness. The invisibility of whiteness is reinforced the colorblind ideology held by many whites, which is discussed in more detail in the next section.

Third, white individuals benefit through their privilege in a variety of ways, including higher incomes, better health, and lower exposure to the criminal justice system (Du Bois 1995; Kobayashi and Peake 2000; Gooding-Williams and Mills 2014; Omi and Winant 2015; Delgado and Stefancic 2017). White privilege is reinforced by cultural practices and social institutions that are also normative in society (Slocum 2007) and it is inextricably linked to the oppression of people of color (Pulido 2000; Delgado and Stefancic 2017; Yancy 2017). It is important to note that white individuals need not hold racists beliefs or commit racist actions to benefit from white privilege (Yancy 2017). The normativity and invisibility of whiteness are part of what make this privilege so powerful and pervasive, regardless of intentionality.

Fourth, Whiteness is a standpoint or way of looking at the world, which is in some cases referred to as white epistemology (Ramirez 2014) or the "white gaze” (Morrison 1992; Kobayashi and Peake 2000; Yancy 2017). From this standpoint, other knowledge and ways of being are viewed as less legitimate. Through the white gaze, whiteness is associated with civilization, positivity, and progress, while blackness an dark skin are associated with evil and savagery (Du Bois 1995; Omi and Winant 2015; Yancy 2017), and the media portrays black individuals and other people of color negatively, as dangerous, criminalistic, or hypersexual (Delgado and Stefancic 2017; Yancy 2017). Yancy defines the white gaze as “that performance of distortional 'seeing' that evolves out of and is inextricably linked to various raced and racist myths, white 
discursive practices, and centripetal processes of white systemic power and white solipsism” (2017:xxxii). Often, this standpoint leads white individuals to feel they need to "show the way” for brown and black individuals and communities, as has been found to be the case within alternative food (Slocum 2007; Guthman 2008; Hoover 2013; Passidimo 2014).

\section{Color-blindness and post-racialism}

The most modern manifestation of whiteness in the United States rests upon a foundational belief that US society has reached a post-racial state and a corresponding viewpoint of colorblindness (Bonilla-Silva 2015). According to Gooding-Williams and Mills:

The majority of white Americans now believe that racial justice has either been fully or almost fully achieved. Thus, there is no further need for measures of preferential treatment and affirmative action, let alone any more radical policy like reparations; and it is diversity, rather than racial justice, that is typically invoked to defend whatever weak programs of corrective reform remain operational. (2014:2)

While the facts differ in terms of continuing (and in some cases increasing) disparities between whites and people of color, this belief is pervasive within the US. Partnered with the notion that we have become a post-racial society is the ideology that aims to ignore the race-based differences in experiences and outcomes between whites and people of color in the US. Bonilla-Silva (2003) has labeled this viewpoint Color-Blind Racism, and claimed that this ideology is based on "a superficial extension of the principles of liberalism to racial matters that results in 'raceless' explanations for all sorts of racerelated affairs” (2015:1364). Bonilla-Silva assures us that this is not the case though, and that racial inequalities are still produced systematically, through practices that are much 
less obvious and visible than previous forms of racism in the US. Doane (2003) asserted that this color-blind ideology is integral to the maintenance of white hegemony in the US, as it combines with the invisibility of whiteness and white privilege to influence the way white Americans see and understand the influence of race.

White privilege and white space

It is plain to modern white civilization that the subjection of the white working classes cannot much longer be maintained. Education, political power, and increased knowledge of the technique and meaning of the industrial process are destined to make a more and more equitable distribution of wealth in the near future. The day of the very rich is drawing to a close, so far as individual white nations are concerned. But there is a loophole. There is a chance for exploitation on an immense scale for inordinate profit, not simply to the very rich, but to the middle class and to the laborers. This chance lies in the exploitation of darker peoples. (Du Bois 1995)

While Du Bois is referencing Germany almost a century ago, the loophole he described has also manifested in the United States. As early as 1920, Du Bois had identified the potential for white privilege to become a dominant force in society, one which was predicated on the oppression of people of color. Over time it has become painfully clear that it is impossible to privilege one group without disadvantaging another, and that white privilege specifically is always tied to the oppression of people of color (Pulido 2000). It is important to look back in time because in addition to being spatial, white privilege is also historical. Understandings of contemporary racial inequities must include historical considerations because racism is no longer overt in the ways it used to be and can no longer be reduced to individual acts (Pulido 2000; BonillaSilva 2015; Omi and Winant 2015). 
As discussed above, white privilege is central to this study in both its

contributions to the phenomenon of whiteness and its direct relationship to the oppression of people of color. One aspect of white privilege that is extremely important for this research is its relation to space. Occupying space is a particular form of white privilege (Kobayashi and Peake 2000) and at the same time a resource in the reproduction of that privilege, because "the full exploitation of white privilege requires the production of space with a very high proportion of white people” (Pulido 2000:16). How spaces are constructed or represented in discourse leads to certain groups feeling more welcome, which is a form of privilege in itself (Pilgeram 2012). Therefore, spaces become coded as white through the bodies that occupy them and the ideas that circulate within them (Slocum 2007; Yancy 2017). Several scholars (Slocum and Saldanha 2013; Ramirez 2014) have used the idea of "viscosity" to explore the way that the presence of mostly white bodies codes spaces as white, as they "stick together" and make the space seem impermeable to people of color.

While whiteness functions through privilege to continue segregation and oppression, it should not be considered only in terms of privilege, as that is just one aspect of whiteness. Though there is much more that can be said about whiteness, the topics covered in this section are the most relevant for this study, including: the underlying colorblindness and post racialist beliefs held by many white individuals; the normativity and malleability of whiteness; its invisibility or transparency to most whites; the way in which it contributes to (and is a product of) white privilege, and therefor white space; and how it is embodied by the white gaze as a way of viewing and understanding the world. These concepts will all be relevant for interpreting the findings of this study, 
as well as for understanding some of the criticisms included in the final section of this review. Before moving on to those criticisms though, it is important to first explore the history and conception of community gardens in the US.

\subsection{Community Gardens in the United States}

Community gardening began as early as the 1890s in the United States, with vacant lot cultivation as a response to rapid migration into cities and a growing demand for affordable food (Lawson 2005; Draper and Freedman 2010; Poulsen et al. 2014). Their popularity has risen and fallen in direct relation to the socio-economic state of the nation, often increasing in in number in response to economic crises (Lawson 2005; Pudup 2008). Community gardens played a central role during both World Wars and the Great Depression, as is highlighted by the rise of Liberty Gardens (WWI), Relief Gardens (Great Depression), and Victory Gardens (WWII) following the onset of each of these events (Lawson 2005; Pudup 2008; Poulsen et al. 2014). Later in the 20th century, community gardens increased in popularity again, this time as a way to combat the decline of urban cities in the 60s and 70s, and by the mid-1990s there were over 15,000 community gardens in the US (Malakoff 1995 as cited by Saldivar-Tanaka and Krasny 2004). More recently, community gardens and other forms of urban agriculture have become commonly used in urban planning (Poulsen et al. 2014) and community gardens have proliferated in many major cities, including New York, Philadelphia, Boston, Chicago, Minneapolis, San Francisco, Seattle, and Portland (Saldivar-Tanaka and Krasny 2004; Lawson 2005; Draper and Freedman 2010). As of 2011, there was an estimated 
18,000 community gardens nationwide (Poulsen et al. 2014), though this is likely a conservative estimate, based on specific definitions of community gardens.

The term community garden is used broadly across a host of academic literature and in popular culture, and applied in varying ways throughout. Some basic definitions are provided that indicate that a community gardens is an organized parcel of land in an urban space, used to grow food and benefit people and community (Ohmer et al. 2009). However, broad definitions such as these do not capture many of the unique characteristics common among most spaces referred to as community gardens. Some scholars argue that the lack of clarity surrounding the phrase is problematic. Pudup (2008) was critical of the way community garden has been used to describe everything from crime diversion gardens to hospital therapy gardens.

Despite this lack of clarity or refined definition, there are several features regularly associated with community gardens throughout the literature which also apply to the gardens included in this study. This does not include the types of garden spaces Pudup (2008) is critical of, such as gardens located at hospitals or prisons, though some of the gardens in the literature and at my research sites are partnered with or located at schools. It is generally accepted that community gardens are distinguished from private gardens by public access, some level of democratic control, and the combined effort of multiple individuals (Draper and Freedman 2010). Contemporary community gardens also regularly function as community meeting spaces as well as places to grow food and other plants. They range from grassroots style models that are community-managed to more institutionalized models that are managed by an outside organization or local government (Saldivar-Tanaka and Krasny 2004). 
Many community gardens are divided into plots owned by individuals, families, or groups, and there are also some that work to grow food more in the fashion of farm, where the harvest is then shared amongst the contributors (Pudup 2008). There are also community gardens that donate some or all of the food they grow to local shelters, pantries, and kitchens. From my own exploration of community gardens in Portland and other cities, I have found that many community gardens that are operated by an outside organization require that an annual fee be paid for temporary ownership of a plot. There are also community gardens that offer free individual plots or group participation, and manage to fund the garden in some other way. Many community gardens, especially those managed by local government or an outside organization, have established rules and regulations in place that govern the practices of the gardeners and operations of the gardens.

Research on community gardens

As was briefly mentioned, community gardens are also included in discussions of urban agriculture (UA) and alternative food. While UA includes a variety of garden or farm projects, community gardens are the most pervasive manifestation of UA at the group level (Poulsen et al. 2014). At an even broader level, community gardens are regularly included in the discourse on alternative food networks, which are defined by shorter distances between the production and consumption of food, smaller scale production, organic or holistic methods, and a focus on sustainability (Jarosz 2008). Discussions of alternative food networks usually include farmers markets and community supported agriculture programs, as well as community gardens and other forms of UA. 
While most of the literature in this review focuses on community gardens specifically, there are some relevant discussions of UA and alternative food networks included as well.

There is a host of research that highlights the benefits of community gardens. In a review of literature on community gardens from the previous decade, Draper and Freedman (2010) found that improved health, food security, economic development, preservation of open space, crime prevention, neighborhood improvement, cultural preservation or expression, social interaction, and community organizing and empowerment were among the most common benefits associated with community gardening. Many of these benefits theoretically extend beyond individual gardeners, to whole communities. Ohmer et al. (2009) claimed that the mere presence of community gardens and other green spaces can facilitate social interaction and cohesion within communities. Other scholars have specifically noted that community gardens have the potential to connect people of color to their cultural heritage (Saldivar-Tanaka and Krasny 2004), and that they provide opportunities for interracial (specifically black and white) interaction where it is otherwise lacking (Shinew, Glover, and Parry 2004). Draper and Freedman (2010:459) argue that “community gardens provide an effective means for community-based practitioners to carry out their roles within the areas of organizing, development, and change.”

However, while the literature on the positive impacts of community gardens abounds, there are also more critical analyses of community gardens and more broadly of UA and alternative food networks. In contrast to the previously mentioned research, Reynolds (2014) demonstrated how the simple presence of a garden does not eliminate 
oppression, though it may alleviate some of the effects of racial disparity, and that in some cases UA and community gardens may perpetuate or reinforce inequality. Similarly, Goodling, Green and McClintock (2015) argue that without explicit measures to confront racial inequality, the sustainability movement's workings can reproduce that inequality. Of alternative food networks, McClintock (2014:148) suggests that “often despite their progressive or radical intentions they are neoliberal in their outcomes, or reformist at best, in that they continue to work within the capitalistic logic of the food system.” Further, Jarosz (2007) points out that alternative food networks such as community gardens, which are often framed around social justice concerns, are not necessarily driven by or actually concerned with those issues. Slocum $(2006,2007)$ is specifically critical of the whiteness of the alternative food movement, which is perceived as more of an issue of diversity within the movement than an effect of the oppression already embedded in the societies in which alternative food networks exist. Viewing racial disparities in terms of diversity, rather than justice, is in line with the notion of post-racialism (Gooding-Williams and Mills 2014) discussed earlier in this review.

Community gardens have also been linked to gentrification (Shinew et al. 2004, Hern 2016), which is one contemporary manifestation of the relationship between privilege and oppression. Gentrification often includes the inflow of privileged whites at the cost of the displacement of people of color and low-income individuals. One prominent example of this complex relationship occurred in New York City in the late nineties, when Mayor Giuliani proposed to sell nearly all of the city’s publicly owned community garden spaces for development (Nemore 1998 as cited by Saldivar-Tanaka and Krasny 2004), many of which were established and operated by people of color in 
low-income communities (Reynolds 2016). While his predecessor, Mayor Bloomberg, compromised in 2002 by preserving 500 of New York’s community gardens, the rest were displaced by new apartments and other forms of development (Steinhauer 2002 as cited by Saldivar-Tanaka and Krasny 2004). Highlighting the connection between gentrification and race, Thrasher (2016) conducted a two-year ethnography of one Brooklyn community garden and found that the garden did not encourage interracial relationship building, as some scholars have suggested they do. Rather, the community garden amplified racial tensions that were related to the rapid gentrification in the neighborhood; rising rents forced some longtime residents of color to leave the area and affluent whites took their place both in the neighborhood and in the garden.

\section{Whiteness in alternative food}

As mentioned briefly above, many scholars have taken a critical approach to examining the whiteness of Farmers Markets (Slocum 2007; Guthman 2008; Pilgeram 2012; Alkon and Vang 2016), community supported agriculture (Guthman 2008), and the broader alternative food movement (Slocum 2007; Henson 2014). Only recently has whiteness been used to examine community gardens, however this is often under the label of UA (Hoover 2013) or other generalizations such as ‘food projects’ (Passidimo 2014), and is still scarce. Within this literature, there is a general criticism of the whiteness of these spaces of alternative food production and distribution. Slocum argues that "while the ideals of healthy food, people and land are not intrinsically white, the objectives, tendencies, strategies, the emphases and absences and the things overlooked in community food that make them so” (2007:526). Guthman (2008) adds that the 
discourse that generally praises white individuals in these spaces also helps to code them as white. Henson (2014) notes that segregation in the broader community makes it difficult for interracial interaction within alternative food spaces and that this helps to maintain their whiteness.

Other scholars point out how even when alternative food projects are created within communities of color, white leadership of these projects increases the potential that they will exacerbate systems of privilege and oppression (Hoover 2013; Passidimo 2014; Bowens 2015; Reynolds and Cohen 2016). Guthman (2008) also notes that the whiteness can be additionally attributed to the colorblind approach taken by much of the white leadership in these spaces, and that further research should focus on the ways that people of color experience exclusion in alternative food spaces. Guthman suggests that a starting point in this work is for white individuals to "state how much they do not know to open up the space that might allow for others to define the spaces and projects that will help spurn the transformation to a more just and ecological way of providing food” (2008:395). However, Alkon and Guthman (2017) point out that despite the pervasiveness of color-blindness and whiteness within alternative food, there is hope as a more race-conscious food activism is on the rise.

Black food space, justice, and resistance

The criticisms of the whiteness of alternative food spaces are of the utmost importance for this study. However, this literature review would be sorely lacking if it did not also recognize that many (mostly black) activists from low-income communities of color have focused on food justice by using alternative food systems as a way to combat 
racial inequality, and explicitly work against the notion that the alternative food movement is exclusively a white thing (Alkon and Vang 2016). Sbicca points out that while whites dominate the alternative food movement, often motivated by localism and sustainability, food justice projects led by people of color contrast this with a focus on racial inequality and "the right of historically disenfranchised communities to have healthy, culturally appropriate food, which is also justly and sustainably grown” (2012:456). Similar to environmental justice, which focuses on preventing the unequal exposure to environmental harm, food justice works to increase equal access to healthy food in low-income communities of color by resisting institutional racism (Alkon and Agyeman 2011).

Food justice projects are founded on an anti-oppression ideology, meant to address racism produced and perpetuated by food systems, and stress the need to create space for local residents to come up with solutions that best meet the needs of their communities (Sbicca 2012). These concepts are also sometimes discussed in terms of food sovereignty, which underscores the need for communities of color to have control over their food systems (McClintock et al. 2018). Alkon and Agyeman (2011) assert that a communities have the right to define their own food systems and means of production and agree that food sovereignty calls for more equal distribution of power in shaping food systems. However, Ramirez (2015) warns that an emphasis on food sovereignty should not replace the food justice ideology because this displaces the focus on the institutional racism that influences food systems and re-centers the place-based motivations of many white food spaces. Regardless of which term is applied, there is an obvious distinction between organizations that aim to conceal racial tensions and those that focus on racial 
inequality and ongoing racism. As Ramirez points out "race, power and privilege emerge through community spaces; they either reify existing inequalities or challenge them, depending on how the food space is being produced” (2014:752).

Often times food justice organizations and spaces are given names that represent a focus on African American culture, such as, “Growing Power, Phat Beets Produce, and the Detroit Black Community Food Security Network” (Alkon and Vang 2016:392). These organizations often connect their work to historical Black Power movements, such as the Black Panthers, who promoted social justice through group buying power and providing lunch to children (Alkon and Agyeman 2011; Burke and Jeffries 2016). Other examples of these historical movements (or what Pulido (2016) has referred to as the Black Radical Tradition) include The Nation of Islam and the Pan African Orthodox Christian Church, which both purchased large plots of land in the 1990s with the goal of establishing a self-sustaining the black community (McCutcheon 2011). More modern examples include the People’s Grocery in Oakland, where anti-oppression training is required for volunteers (Sbicca, 2012). Additionally, Clean Greens in Seattle “pushes a politics that is proudly black” and creates black food spaces (Ramirez 2014:756), while Chicago’s Healthy Food Hub and Oakland’s Mandela Marketplace resist critiques of alternative food as “elitist” (read: white) by working within an African American cultural framework that puts issues of race, health, and community development at the top of their list. They work to combat racialized oppression within their communities and depend on black leaders and black representation in their organizations to code them as black spaces (Figueroa and Alkon 2017). Other food justice scholars (McCutcheon 2011; Hoover 2013; Passidimo 2014) agree that black leadership is needed in organizations and spaces 
that intend to benefit black communities. Similar projects geared towards the Latinx community are becoming more common as well (Ramirez 2014; Alkon and Vang 2016).

Many of these organizations encourage resistance to historical trauma and ongoing oppression, are a source of community and individual empowerment, and provide spaces in which to resist negative images and stereotypes (Reynolds and Cohen 2016; Figueroa and Alkon 2017). The concept of historical trauma has been identified as a "large scale, systems-related, macro-stressor" that negatively impacts the well-being of a specific racial or ethnic group (Williams, Neighbors, and Jackson 2003 as cited by Sotero 2006:96) as well as "the cumulative and collective psychological and emotional injury sustained over a lifetime and across generations resulting from massive group trauma experiences” (Brave Heart 2003). Based on a review of the literature on historical and intergenerational trauma, Sotero (2006:94-95) suggested four main assumptions underpin the theory of historical trauma:

(1) mass trauma is deliberately and systematically inflicted upon a target population by a subjugating, dominant population; (2) trauma is not limited to a single catastrophic event, but continues over an extended period of time; (3) traumatic events reverberate throughout the population, creating a universal experience of trauma; and (4) the magnitude of the trauma experience derails the population from its natural, projected historical course resulting in a legacy of physical, psychological, social and economic disparities that persists across generations.

Slavery is the most obvious source of historical trauma for African Americans, but trauma has also resulted from (and been connected to) more recent historical events, such as waves of "urban renewal” across the US that disproportionately burdened black communities (Fullilove 2001).

While community gardening or the act of growing food can relate to previous trauma or oppression for people of color, it can also provide a therapeutic space. Bowens 
(2015) highlighted the legacy of oppression that has been bound to agricultural for people of color in the US, and illustrated some examples in which they are using agriculture to heal and resist these forces in rural cities across the US. Reynolds and Cohen (2016) documented similar efforts and actions in the more urban environment of New York City. Figueroa and Alkon highlight this notion as well, stating that growing food is "not only a way to connect to the earth, as it often is for alternative food movements, but also a way to heal the trauma associated with forced agricultural labor and to empower a community through reimagined and reclaimed foodways” (2017:217). The spaces created by these organizations are therefore not only beneficial to the communities they serve, but may be therapeutic to the people of color who spend time in them.

Case has suggested that spaces such as these should be dubbed “counterspaces” and claims that they "promote the psychological well-being of individuals who experience oppression” "by challenging deficit-oriented societal narratives concerning marginalized individuals identities” (2012:257). Reynolds and Cohen (2016) also highlight examples where urban farms and gardens provide "safe spaces" for women of color, LGBTQ individuals, and previously incarcerated youth. For people of color, these counterspaces are even more important in places that are extremely white, as the constant exposure to whiteness can be a form of oppression or trauma in itself. This is illustrated quite well by Richard Wright, when he writes of experiences with whiteness from his childhood,

It was as though I was continuously reacting to the threat of some natural force whose hostile behavior could not be predicted. I had never in my life been abused by whites, but I had already become as conditioned to their existence as though I had been the victim of a thousand lynchings. (1947:65) 
Thus, these black food spaces serve a multitude of purposes for black communities, acting as counterspaces where individuals can have a therapeutic experience and resist negative stereotypes of the black identity, and providing a platform to work towards food justice and community empowerment.

\subsection{Portland, Oregon}

Before describing the community garden scene in Portland, it is necessary to establish some important history in order to understand the racial formation of the city. This history will help to illuminate some of the racial projects that have shaped Portland, and influenced the way individuals perceive the racial dynamics of the city. According to Omi and Winant, “a racial project is simultaneously an interpretation, representation, or explanation of racial identities and meanings, and an effort to organize and distribute resources along particular racial lines” (2015:125). This history will also help to provide an understanding of how interactions, spaces, and processes became racialized, or how they were given racial meaning through historical processes. Because black community gardeners in Portland constitute the population of this study, the history of black communities in Portland is especially important for this research. A thorough understanding of this history will allow for a more nuanced interpretation of the individual experiences of the gardeners who participate in this project.

Both the city of Portland and state of Oregon have had extremely racist pasts. While these prejudices may have simply evolved over time into more subtle forms, more aggressive, unabashed types of racism and discrimination were prevalent for over a century in Portland and across the state. One of the earliest historical instances of state 
oppression of black people in Oregon was marked by the passage of laws in 1844, which banned slavery and simultaneously made it illegal for black individuals to reside in the state, or even to be in it after sundown (Bates et al. 2014). These laws were slightly amended with the adoption of the state constitution in 1857, which barred black individuals who weren’t already in the state from living in Oregon (Bates et al. 2014), and again in 1866, when the 14th amendment was passed and ratified in Oregon. While the $14^{\text {th }}$ amendment granted all US born individuals citizenship, which theoretically made it legal for black individuals to move into the state (Bates et al. 2014), Oregon rescinded its ratification in 1868 did not fully ratify the 14th amendment until over 100 years later in 1973 (Hern 2016). The clause in Oregon's constitution banning black people from coming to and living in the state was not officially removed until 1926 (Gibson 2007). By 1900, there were just over 1,100 African Americans living in Oregon and about two thirds of them resided in Portland. Just two decades later the nationwide KKK revival made its way to Portland and was embraced by at least 35,000 card carrying members (Burke and Jeffries 2016). Their reign ended within the decade due to internal contention and corruption, though Klan parades were common in Portland during this time and crosses were burnt atop Mount Scott. In 1923, a KKK member was elected Governor of the state (Burke and Jeffries 2016). Despite this terror-ridden climate, though, an African American community continued to grow in Northeast Portland and nearby areas. By the 1930s, the black community in Portland was thriving with a black physician, black dentist, and multiple black lawyers and ministers (Bates et al. 2014). WWII drew even more African Americans to Portland to work in the shipyards. The population of Portland grew rapidly during this time, which led to the creation of 
Vanport City as a temporary housing solution. The general attitude was that if more black people were coming to Portland there needed to be a place for them, and the white majority didn’t want black people moving into their neighborhoods (Burke and Jeffries 2016). Vanport was constructed in a hurry, in an undesirably low-lying area of land right next to the Columbia River. Many of the black individuals and families that arrived in Portland were funneled directly into the temporary city. Vanport flooded in 1948, after a railroad berm that doubled as a dike broke, and massive amounts of water rushed into the city. Over a third of the population of Vanport (about 17,000 people) was black when it flooded (Burke and Jeffries 2016), in stark contrast to the rest of Portland. Housing was already an issue for the black community and ineffective rehousing strategies by the local and state government only added to this problem. The flooding of Vanport led to further growth of the black community in North Portland, as many of the black individuals who were forced to evacuate were funneled into the Albina District. In 1950, almost half of the 10,000 black people living in Portland resided in Albina (Burke and Jeffries 2016). Portland's black population rose to about 15,600 a decade later with just under three quarters of those living in Albina. This did not happen by chance; the boundaries of Albina were maintained through physical violence, de facto segregation, redlining, and discriminatory lending practices which perpetuated the racial inequality in Portland (Gibson 2007; Hern 2016).

In the 1950s the city's construction of the Memorial Coliseum and Interstate 5 fractured the black community, as hundreds of homes and businesses in the area were demolished and families were forced to relocate without assistance from the city (Burke and Jeffries 2016). Portland's black community was further devastated by development 
initiated by the Portland Development Commission (PDC), which was created in 1958. Through the Central Albina Plan and other efforts, the PDC targeted Albina for urban renewal projects that were the primary force of destruction to the black community for over a decade (Burke and Jeffries 2016). While the community was able to pressure the city into creating the Citizens Planning Board as a means of having input into the efforts of the PDC, this only had a minor impact as internal leadership and funding struggles kept the Planning Board from having much influence. The PDC dealt another blow to the black community by demolishing homes and businesses for the expansion of Emanuel Hospital, which was abandoned in the mid-70s due to lack of federal funding (Burke and Jeffries 2016).

Disinvestment continued into the 1980s and the neighborhood continued to decline, as drug traffic from Los Angeles led to increase drug use and violence in the neighborhood, including added police violence from the "war on drugs.” During this time, the black population decreased in Albina; many of those who could afford it began to leave the area (Gibson 2007). In 1990, African Americans still made up about three quarters of Albina (Hern 2016) but the city renewed its urban renewal efforts in the area and this attracted many young whites who were easily able to get loans for businesses and homes and take advantage of the rock bottom property values. The City's efforts, through the PDC (now Prosper Portland) and initiatives such as the Interstate Corridor Urban Renewal Area (Portland Community Gardens Program 2001) and the Albina Community Plan, directly spurred the gentrification that is the most recent source of displacement for the black community in Portland, and perhaps most devastating (Hern 2016). These same initiatives provided funding to institutionalize Beech Community 
Garden (Portland Community Garden Program 2001), and other community gardens in and near Albina.

Hern (2016) claimed that Albina is the starkest example of displacement fueled by gentrification in the US. By the end of the century, new white homeowners were rapidly displacing black families (Gibson 2007), and by 2010 less than a quarter of Albina residents were black. The city has taken some small efforts to address the issue of displacement, such as developing affordable housing in the Albina district that gives preference to individuals who have ties to the community and are at risk of being, or have already been, displaced (City of Portland 2015). However, many black individuals and families who did not leave Portland have been scattered about in areas such as East Portland, where amenities including public transit, grocery stores, and community gardens are less common (Hern 2016). The increased development in Albina, beginning in the 1990s, has been accompanied by a general neglect of East Portland, and this uneven development of the city allows for racialized disparities to persist and grow, as the less affluent communities of color are funneled into that area (Goodling et al. 2015).

Albina is an important focal point of Portland's history and racial formation because it was the center of so much of the oppression faced the by the black community, via systemic and structural racism, and the site of many racial projects on behalf of both black and white communities and individuals. The history that unfolded in Albina demonstrates some of the types of racialization that occurred over the past century, including the racialization of housing, education, and law enforcement. As Bates et al. noted, 
African Americans in Multnomah County continue to live with the effects of racialized policies, practices, and decision-making. The stress of racism has a profound impact on health and wellness, as do other social determinants of health, such as ongoing discrimination in housing, school discipline, and racial profiling by police. (2014:2).

Bates et al. (2014) also demonstrated that white families income is more than double that of African American families and that African Americans are almost twice as likely to be unemployed (2009 data). The report also showed that the poverty rate for African American youth is more than three times that of white youth, and African American children are more likely to be placed in foster care, less likely to finish high school, and are more than six times as likely to be charged with a crime as white youth. In regards to property ownership, about twice the percentage of white households own their homes and the report mentions that this likely related to the displacement resulting from the gentrification of the Albina District (Bates et al. 2014). The displacement of black individuals from this part of Portland has been predicated upon the influx of white individuals whose privilege allowed them to easily buy property in the area.

Despite the small size of Portland's black population, these glaring disparities are an unfortunate reality of Portland's current racial dynamics, and a process of the racial formations that have taken place here. According to the 2010 Census about $6.3 \%$ of Portland's population was black and about 75\% were white (census.gov 2018). Historically, Portland's black population has never exceeded 7\% and Oregon's has never exceeded 2\% (Gibson 2007) and Portland is the whitest metropolitan city in the United States (Renn 2009 as cited by Hern 2016). While some may view such a homogenous city as a poor place to study race, the racial projects and processes of racialization that have occurred over the last two centuries have contributed to the overwhelming 
whiteness if Portland, making it an opportune place to study the impacts of that very whiteness. One of the spaces that have become racialized over time as part of the process of racial formation are Portland's community gardens. These spaces will be the focus of this research, and are introduced in the following and final section of this review.

\section{Portland's community gardens}

The City of Portland operates more than 50 gardens via the Bureau of Portland Parks and Recreation. Criticisms of the whiteness of alternative food spaces can easily be applied to many of Portland's community gardens, especially in those managed by PPR where less than 2\% of plot-holders identified as black in 2016 (Portland Parks and Recreation 2016).

\begin{tabular}{|lcc|}
\hline \multicolumn{3}{|c|}{ Table 1: Race/Ethnicity for PPR community garden plot-holders (2016) compared to (2010) Census Data } \\
\hline Race/Ethnicity & \% of PPR plot-holders & \% of Portland population \\
White & 69.5 & 76.1 \\
Black/African American & 1.6 & 6.3 \\
American Indian\& Alaskan Native & 0.3 & 1 \\
Asian & 7.6 & 7.1 \\
Native Hawaiian and Pacific Islander & 0.2 & 0.5 \\
Hispanic or Latino & 6.6 & 8.4 \\
Other race & 2.2 & 4.2 \\
Multi-racial & 4.4 & 4.7 \\
Declined & 7.4 & - \\
\hline
\end{tabular}

*Due to some overlapping categories, census total exceeds $100 \%$

Many of the community gardens under the purview of PPR were created with an understanding of community gardens that is consistent with the literature on the theoretical benefits community gardens provide. One example of this comes from a grant recommendation from Friends of Portland Community Gardens, an outside organization that works with the City’s program to further the development of community gardens 
throughout the city. A letter from one of the organizations Co-Chairs, sent to the City’s Bureau of Housing and Community Development in support of a grant that the Portland Community Garden Program applied for, claimed that "community gardening can play a pivotal role in maintaining the stability and livability of our city and would be of special value in an area deficient in clean, safe open space in this economically modest neighborhood," (Friends of Portland Community Gardens 1995). The City’s Community Garden webpage states the following:

The Community Gardens program has provided gardening opportunities for the physical and social benefit of the people and neighborhoods of Portland since 1975. There are 53 community gardens located throughout the city, developed and operated by volunteers and Portland Parks and Recreation staff, offering a variety of activities.” (Portland Community Gardens Program 2017).

Despite the seeming abundance of community gardens in Portland, applicants for PPR's community program are often put on a waiting list. Prices for plots range from fifteen dollars for a 50 sq. foot “starter plot” to $\$ 200$ for an 800 sq. foot plot. There are also scholarship opportunities for low-income individuals that can cover up to $75 \%$ percent of the cost, which have been distributed to more and more gardeners each year. Participation in the garden requires adherence to a set of rules that can be found on their website, and are also posted on bulletin boards at some gardens. Some of the practices in the program, including enforcement strategies, are very elaborately planned out, as pictured here. 
Figure 1: Portland Parks and Recreation Gardener Reminder Chart

\author{
$\leqslant$ PORTLAND PARKS \& RECREATION \\ Healthy Parks, Healthy Portland
}

\title{
How Garden Plot Reminders work:
}

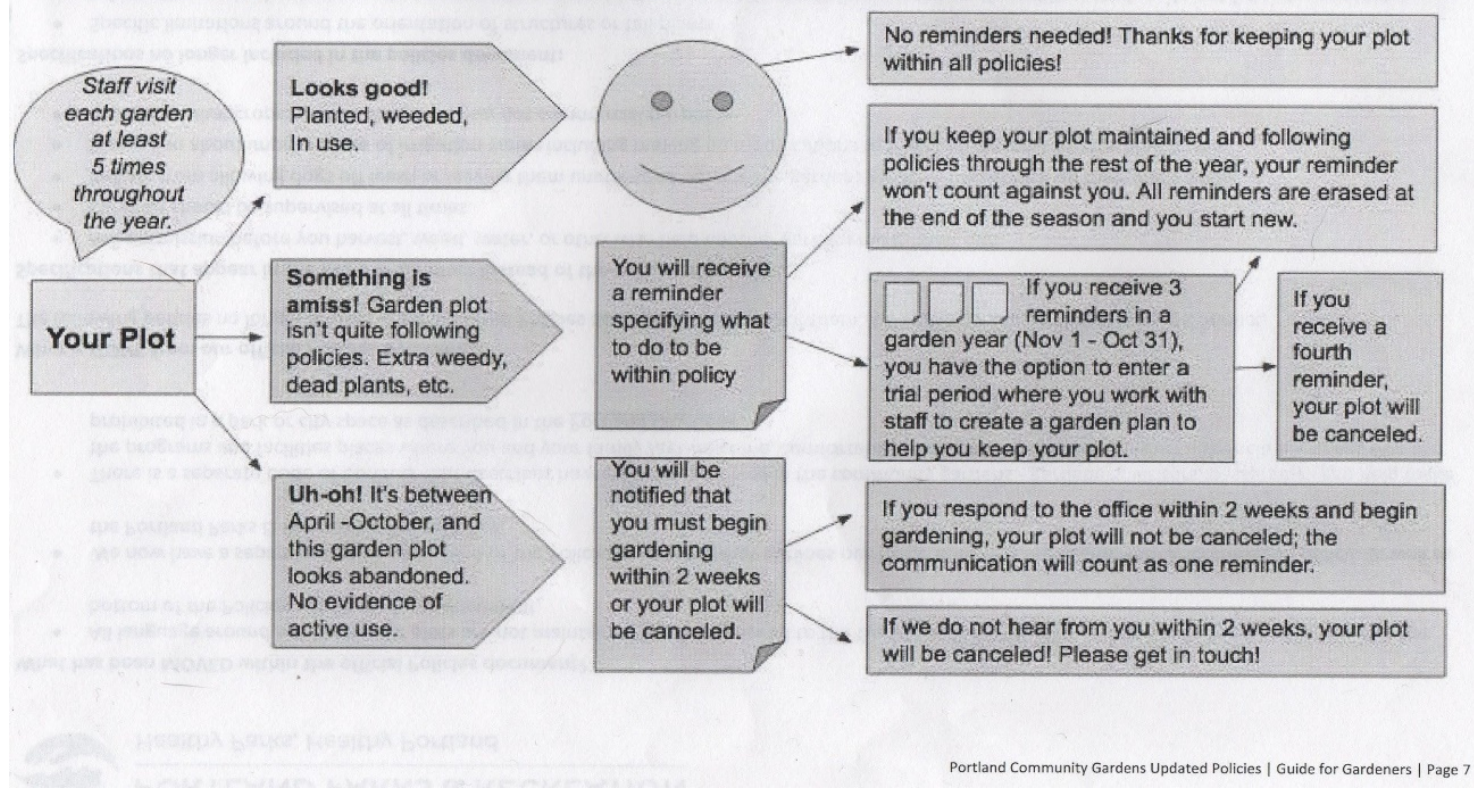

There are an abundance of community gardens operating outside of the

jurisdiction of PPR as well, though the exact number is difficult to pin down. There are two organizations in Portland that work to establish and operate community gardens (Grow Portland and Outgrowing Hunger) as well as individual gardens operated by community organizations, churches, and schools. There are also food justice projects and spaces, similar to the ones described in the previous section, many of which have been spearheaded by Portland's black community. Some examples of these include the Urban Harvest Garden (Urban League of Portland 2017), the June Key Delta Garden, and MudBone Grown (Multnomah County 2017), which all work to empower the black community and increase their access to healthy foods. 
The City of Portland has generally viewed the development of bike lanes and community gardens as an improvement that would help overcome current "disparities” (Mendes et al. 2008). While many people in Portland accept community gardens as a regular and beneficial feature of the city, some residents (especially members of the black community) view the community gardens as a symbol of gentrification, along with bike lanes (Lubitow and Miller 2013; McClintock et al. 2018). Recent research in Portland has found that UA, at least at the residential level, is directly tied to ongoing gentrification in the city (McClintock et al. 2016; McClintock et al 2018). One individual from Portland was quoted in a recent publication, saying ““...the community gardens. That’s another bad sign for the African American community. We always gardened. We always shared our gardens and our food. We didn’t need 'community gardens.' That's a white invention'” (as quoted in Hern 2016:10). The black community’s turbulent history in Portland, especially as it relates to past efforts at development, helps to explain this perspective. This may be one of the factors leading to such a low number of black individuals gardening in Portland's community gardens, as they have come to symbolize ongoing displacement and marginalization of the black community.

These conflicting understandings of what effect community gardens have in Portland beckons inquiry into these topics, as well as an exploration of how these interpretations influence black community gardeners. The CRT framework encourages the valuing of experiential knowledge and the 'voice of color' shared by people of color (Delgado and Stefancic 2017) and whiteness and its effects are usually invisible to whites (Delgado and Stefancic 1997, 2017; Doane 2003). Black community gardeners will therefore likely have the most valuable and informed perspectives on the way whiteness 
influences their participation. This research will also help to fill gaps in the literature pointed out by previous scholars (Guthman 2008; Hoover 2013) who have called for the inclusion of perspectives of marginalized groups in the study of UA, and a more thorough understanding of how these individuals experience oppression in these spaces. Thus, this study proceeds with the following research questions: (1) How do black individuals experience community gardens in Portland, Oregon as racialized spaces? (2) How are black gardeners’ practices and participation in urban agriculture in Portland influenced by racism and whiteness? (3) In what ways do the features of a community garden influence black individuals’ participation in Portland? 


\section{RESEARCH METHODS AND DESIGN}

Of [the Souls of White Folk] I am singularly clairvoyant. I see in and through them. I view them from unusual points of vantage. Not as a foreigner do I come, for I am native, not foreign, bone of their thought and flesh of their language. Mine is not the knowledge of the traveler or the colonial composite of dear memories, words and wonder. Nor yet is my knowledge that which servants have of masters, or mass of class, or capitalist of artisan. Rather I see these souls undressed and from the back and side. I see the working of their entrails. I know their thoughts and they know that I know. This knowledge makes them now embarrassed, now furious. They deny my right to live and be and call me misbirth! My word is to them mere bitterness and my soul, pessimism. And yet as they preach and strut and shout and threaten, crouching as they clutch at rags of facts and fancies to hide their nakedness, they go twisting, flying by my tired eyes and I see them ever stripped,ugly, human. (Du Bois 1995:453)

\subsection{Project Design}

While it had not yet been given the name, Du Bois was describing what can now be referred to as the Outsider within Epistemology, which informs the methodological approach of this research. While Du Bois may have written about this way of knowing decades earlier, it was not until the 1980s that Patricia Hill Collins (1986) elaborated on an epistemology unique to black women, and dubbed them 'outsiders within'. Collins recognized that black women's outsider status within academia, as well as within society at large, provided them within a special standpoint or "angle of vision" that generates unique knowledge. The Outsider within Epistemology is similar in some ways to Feminist Standpoint Epistemology (Harding 1986), although it takes more into account the intersectional nature of oppression (Crenshaw 1995; Collins 2000), or what Collins calls “interlocking oppressions” (Collins 1986). Sarah Harding (one of the leading 
scholars of Feminist Standpoint Epistemologies) was aware of the need for a more intersectional approach and asked:

Can there be a feminist epistemological standpoint when so many women are embracing 'fractured identities' as black women, Asian women, Native American women, working-class women, lesbian women? Do not these identities undercut the standpoint assumption that common experiences as women create identities capable of providing the grounds for a distinctive epistemology and politics? (1986:163)

For Collins, this standpoint was based on black women's status as outsiders more so than on the commonality of their experiences. Collins (2000) believed that this type of knowledge should be institutionalized within Sociology as a way of uncovering aspects of reality not readily visible using traditional approaches, and she is not the only scholar in support of this type of epistemology.

George Yancy, a Philosopher of racism and whiteness claims that black individuals make up an epistemological community. He asserts:

From the perspective of an oppressed and marginalized social position, Blacks do in fact passes a level of heightened sensitivity to recognizable and repeated occurrences that might very well slip beneath the radar of others who do not have such a place and history in white dominant and hegemonic society. (Yancy 2017:23)

The Outsider within epistemology has been used in numerous other studies as well, to explore the experiences of African American women firefighters (Yoder 1997), black female college athletes (Bruening 2005), female principles (Hargreaves 1996) and Mexican and Korean American youth (Kwon 2015). One researcher (Flores 2016) even used the concept of the outsider within to conduct a reflexive analysis of how their own identity, as an outsider within, influenced their data collection. As the literature demonstrates, this epistemology is a powerful tool that can be adapted to various types of qualitative research. 
Within the CRT framework, a very similar concept is referred to as counterstorytelling, in which “counterstories” are used to challenge or dispute normative beliefs and dominant narratives, often using a “voice of color” (Delgado and Stefancic 2017). Multiple scholars (Daniels 2007; Reynolds and Mayweather 2017) have taken a novel approach in critical studies of college education and combined these two concepts, interviewing outsiders within and sharing their counterstories. This research employs a similar approach, sharing the experiences of outsiders within in order to offer a narrative that is counter to dominant beliefs about Portland and its community gardens. By interviewing black community gardeners, this study aims to uncover information about whiteness that is likely invisible or unrecognized by most white community gardeners, who may view the world through the white gaze.

While interviews have previously been used to study community gardens (Glover 2004; Saldivar-Tanaka \& Krasny 2004; Shinew et al. 2004; Ohmer et al. 2009; Poulsen et al. 2014) and other alternative food spaces (Pilgeram 2012; Guthman 2008; Alkon \& Vang 2016), much of this research has focused on mostly white samples. While some of the previous research does include people of color (Glover 2004), these studies have been less critical of power differentials and largely failed looked at the impact of whiteness on people of color in these food spaces, excluding a small number of exceptions (i.e. Ramirez 2014). Critical scholars of alternative food claim that more research is needed to understand how and to what degree people of color experience exclusion in those spaces (Guthman 2008), and how these spaces and the systems around them can become more inclusive to people of color and ultimately less racist (Slocum 2007; Pilgeram 2012). This 
study seeks to fell this gap within the literature by highlighting the experiences and sharing the knowledge of outsiders within the movement.

The Outsider within epistemology is also an ideal approach for exploring whiteness because it helps to avoid the centering or essentializing of whiteness, which has been one of the major pitfalls of previous whiteness studies. Some of the literature has been critical of the over-application of whiteness to explore white identity, rather than exploring how whiteness relates to power and oppression (Anderson 2003; Lewis 2003; Yancy 2017). Yancy warned that white scholars must be especially careful to avoid recentering whiteness at the cost of losing touch with the "real world of weeping, suffering, and traumatized black bodies impacted by [whiteness]” (2017:220). Anderson (2003) noted that much of the literature tends to avoid "material realities" created by race and that a stronger efforts needs to be focused on the racialized privilege generated by whiteness. Lewis (2003) argued that studying whiteness is critical for the development of racial equity, but agrees with Anderson (2003) that whiteness should be used to study power relations rather than essentializing whiteness. Exploring the experiences and perspectives of black community gardeners in regards to the whiteness of community gardens helps to avoid this pitfall. It also helps to fill an important gap highlighted within the literature (Slocum 2007, Guthman 2008, Pilgeram 2012), in which the effect the whiteness of alternative food spaces have on black individuals and other people of color have been generally neglected or overlooked. 


\subsection{Data Collection}

The data for this project was primarily gathered using semi-structured, in-depth interviews of black and African American adult individuals who participate in community garden spaces in Portland, Oregon. As outsiders within both Portland (a mostly white city) and community gardens (a mostly white, alternative food space), these individuals were asked about their experiences in the gardens (both negative and positive), perceptions of the space and other gardeners, and also about the impact these factors had on their activities, participation, and overall experience. As a means of triangulation (Creswell \& Miller 2000), I spent multiple periods of extended observation at 10 community gardens (about 60 hours in total) in Portland and took field notes detailing my observations and encounters with gardeners not included in the sample of this study. While I visited many other gardens briefly, these 10 were the focus of my observations. I initially aimed to spend more time at a select few gardens, but like some previous researchers (Saldivar-Tanaka \& Krasny 2004), I found that spending more time at fewer gardens did not offer any better insight into their dynamics than did spending shorter times at a larger number of gardens. This was especially true once gardens outside the purview of PPR were included in the study, as the differences between gardens became a valuable point for comparison, as opposed to the internal dynamics of only a few gardens. 
Table 2: Research Sites, Participants, Observation, and Racial Coding

\begin{tabular}{|lccc|}
\hline Research Site & \# of gardeners interviewed & \# of hours observed & Black or white space? \\
\hline Garden 1 (PPR) & 2 & 5 & W \\
Garden 2 (PPR) & 1 & 6 & W \\
Garden 3 (PPR) & 1 & 7 & W \\
Garden 4 (PPR) & 1 & 8 & W \\
Garden 5 & 2 & 4 & B \\
Garden 6 (PPR) & 1 & 6 & W \\
Garden 7 & 2 & 7 & - \\
Garden 8 (PPR) & 1 & 4 & W \\
Garden 9 (PPR) & 1 & 4 & W \\
Garden 10 & 2 & 8 & B \\
\hline
\end{tabular}

* Three participants gardens were not observed

Figure 2: Map of Research Sites

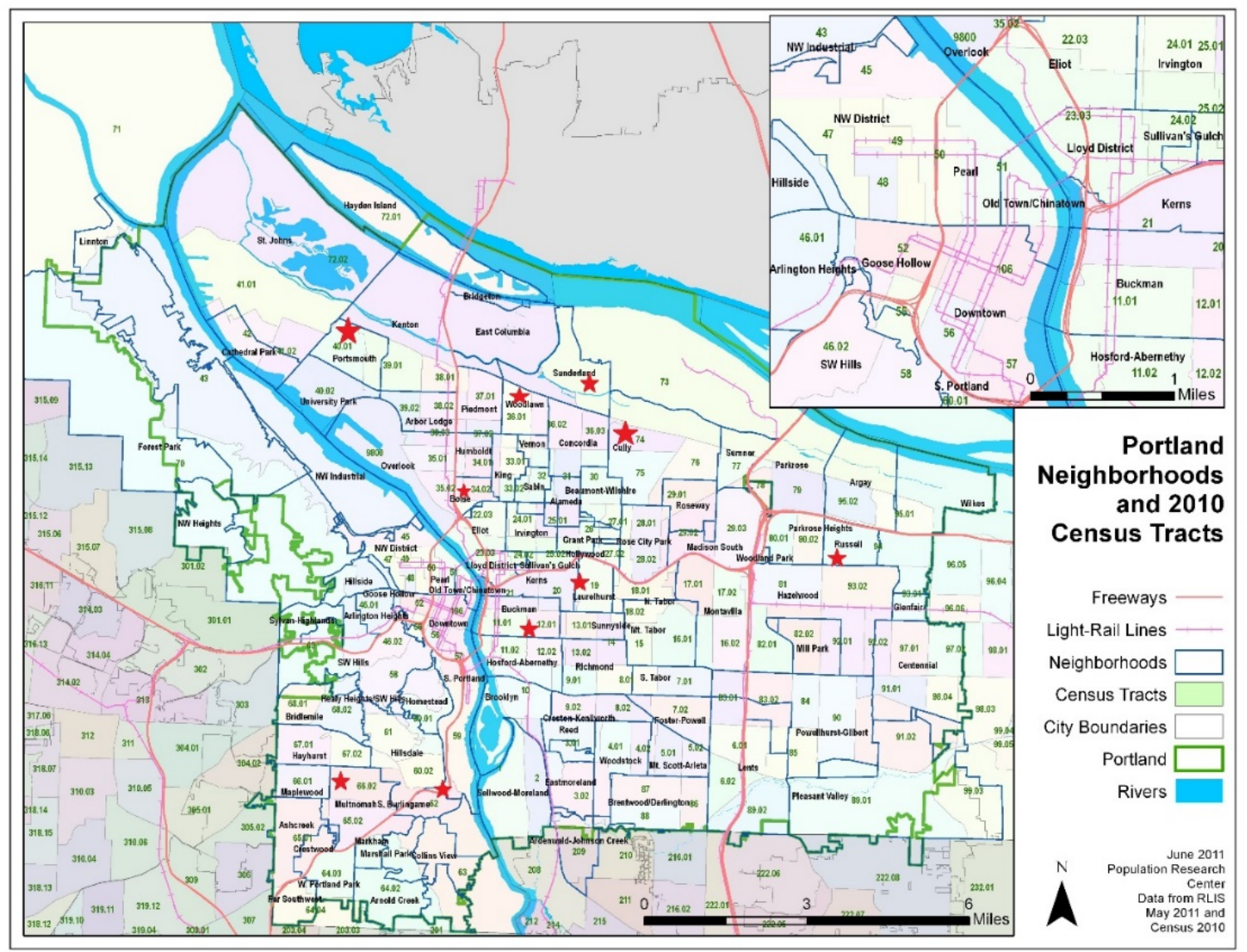


I had originally hoped to spend more time gardening alongside gardeners as a participants, but I was only able to achieve this twice and most of my observation was spent sitting or walking around the gardens. I collected field notes on my observations, both before and after interviews, as well as during visits and periods of observations at the gardens. In addition to the 17 interviews, I also had many interesting encounters with gardeners and neighbors of gardens. While the experiences of the gardeners I interviewed are the primary source of data, some of the findings I discuss in the next section are largely informed by my own observations and these other secondary sources of data. Information shared by the previous and current program directors of the PPR community garden program and a review of grant documents for some of PPR's gardens have contributed to this study as well. These multiple sources of information provided me with a nuanced understanding of Portland's community gardens as well as insights into the structure and ideologies of PPR's community garden program.

The in-depth interviews were semi-structured, following an interview guide but also allowing for deviation from the guide. Whenever possible I allowed the participant to lead the interview, only referring to the guide as needed. Questions on the interview guide were generated drawing on knowledge from previous research, and in an effort to answer the research questions guiding this study. The interviewees were asked about their experiences in the community garden, including questions about relationships with other gardeners, their motivations for participation and how the garden affects them. They were also asked questions about their lives that may relate to their experiences, such as how long they have lived in Portland, if they live near their garden, and why they garden. Finally, interviewees were asked about the racial dynamics of their garden and any 
changes they would make if they were able to. In an attempt at snowball sampling, respondents were asked if they know any other black community gardeners that would like to be interviewed.

Between August and December of 2017, a total of 17 gardeners from 13 different gardens were interviewed at the interviewees' garden or a nearby location, as preferred by the interviewee. Participants were recruited using a purposive convenience sampling approach and outreach included posting flyers at community gardens, publishing a newspaper ad, emailing community garden managers, and snowball sampling. Several participants were also recruited in person during periods of observation at some gardens. The gardens of interest for observation and recruitment were initially identified using the demographic data that the PPR community garden program had previously gathered, which specified the race of each plot-holder. There were a total of 26 plot-holders who identified as black, African, or African American during the 2016 growing season, and the 6 gardens with two or more of these individuals were included as initial study sites. Other gardens outside of the PPR system were eventually identified as potentially having multiple black or African American community gardeners, and were included in recruitment and observation efforts as well.

To maintain the confidentiality of the research subjects, all interviewees were assigned a pseudonym to be used through the duration of the study. Informed consent was granted by all participants, and all interviews were digitally recorded and fully transcribed by the researcher or research assistant. The interviews ranged in length from 21 to 70 minutes, with an average of 41 minutes. Of the 17 individuals interviewed, 7 identified as black, 4 identified as African, 2 identified as African American, 3 identified 
with more than one race or ethnicity, and 1 simply identified as American. 6 of the individuals in the sample identified as male, while the other 11 identified as female. Interviewees ranged from 33 to 66 years old and the average age within the group was 46 years old. Other demographics, including highest level of education, relationship status, household size, and estimated income all varied within the sample, as indicated in the table below.

\begin{tabular}{|lccc|}
\hline Table 3: Descriptive Statistics & \multicolumn{2}{c|}{} \\
\hline & \multicolumn{2}{c|}{$\begin{array}{c}\text { Mean or } \\
\text { Frequency }\end{array}$} & \\
\cline { 2 - 2 } Age & 46 & Education & Frequency \\
\cline { 2 - 3 } Household size & 3.8 & LTHS or HS & - \\
Female & 11 & Some College & 3 \\
Single & 6 & Bachelor's Degree & 4 \\
Race/Ethnicity: & - & Graduate Degree & 4 \\
Black & 7 & 2016 HH Income & - \\
African American & 2 & $<\$ 10,00$ & 2 \\
African & 4 & $\$ 10,000-\$ 49,999$ & 6 \\
Mixed Race & 3 & $\$ 50,000-\$ 99,999$ & 5 \\
"American" & 1 & $\$ 100,000$ or more & 2 \\
\hline
\end{tabular}

\subsection{Data Analysis}

The analysis of the data for this study proceeds using the general inductive approach, which allows the researcher to "establish clear links between the evaluation or research objectives and the summary findings derived from the raw textual data” and offers a procedural way to analyze qualitative data that can generate valid and reliable results (Thomas 2006:237). The use of this approach enables findings to develop from intrinsic themes in the data without the restrictions imposed by some other, more technical types of analysis. After transcribing the interviews (with some assistance), I thoroughly read each transcript and all field notes. Next I created an initial coding scheme, which focused on potential concepts that were relevant to the research questions, 
such as benefits, motivations, social inclusion, whiteness, racism, barriers, and exclusion.

Within these initial codes, sub codes were determined based on the readings of the interviews and field notes.

Ultimately, this analysis aimed to offer an understanding of the shared experiences of black individuals who participate in Portland's community gardens. If codes outside of this scheme emerged and became relevant to this goal, they were added to the coding scheme. Field notes associated with specific interviews were coded with their corresponding transcription. The coding process was conducted using Dedoose coding software, and after coding was complete the coding scheme was refined to reduce overlap and redundancy. Finally, I created thematic models to address my research questions using the most relevant codes and information gathered through the coding process. My final codebook included 33 codes in total, with 7 parent codes and 26 child codes. The parent codes functioned as categories or themes that were then directly incorporated into the findings in the following chapter, and supported with selected quotes that were coded to those categories.

\subsection{Advantages and Limitations}

One of the expected limitations of using in-depth interviewing in this study was the identity of the researcher. As a white male interviewing black individuals based on their status as marginalized individuals, there were likely race of interviewer effects at play. Ironically, my own status as an outsider within the community I was engaging may have made participants less willing to divulge critical perspectives and opinions. This felt especially true of the four African participants in the study, who had little to nothing 
critical to say about their experiences as community gardeners, mostly expressing their gratitude for being given access to such a space. Similarly, because of the historical and ongoing displacement of the black community in Portland, which is now largely personified by young white gentrifiers, my age may have also had a negative impact as I was younger than any of my interviewees. Finally, my lack of immersion in the community of community gardening and urban agricultural previous to this study may have further cast me as an outsider to those who were more involved. While this study was an important one that yielded valuable results, an older person of color who was previously engaged in the urban garden community would likely have been able to access an even greater amount of information.

This methodological approach also has its advantages. The largely white population in Portland makes it an exceptional location for exploring the concept of whiteness and its impact on black individuals. Though Portland's black community is much smaller (and now more dispersed) than many other urban cities, they are an extremely resilient one with a bounty of outspoken community members and a welldocumented history in the city and state. With active organizations like the Urban League, NAACP, and the Portland African American Leadership Forum (PAALF) it is obvious that the black community continues to demand a voice in Portland. Additionally, a focus on the Outsider within Epistemology prevents this research from centering and essentializing whiteness, which has been a pitfall in previous studies of whiteness. 
4 FINDINGS: WHITENESS AND PORTLAND’S COMMUNITY GARDENS

In this chapter, I will argue that many community gardens in Portland are white spaces. They can be understood as such by their observed congruence with previous literature, and by the way this whiteness is experienced by the black community gardeners I interviewed. Aside from the two gardens I spent time observing that identified as explicitly black garden spaces, the rest of the gardens included in this research were ultimately white gardens. For many of the black gardeners I interviewed, the racialization of these gardens influenced their participation in them. Several black gardeners described having avoided gardens they perceived as white and several of the individuals I interviewed had left their community garden (or moved to a different one) because of direct oppressive experiences related to whiteness, such as microagressions and cultural marginalization.

Despite that nearly all interviewees who had gardened in a white space described being aware of this whiteness to some extent, there were several gardeners who actively chose to ignore or tolerate it. In these cases, the individual gardeners’ level of engagement with the space varied from heavy engagement, to mostly keeping to themselves. While not all interviewees were equally explicit in the way they described the whiteness of the gardens, some gardeners had no problem providing that verbatim description. While discussing the community gardens nearby in the Albina neighborhood, Tamica said "there's another garden that may be ten blocks away from there. I think that's in a Portland Park and Rec space, and that's very white as well.” This is an example of how gardens can be perceived or coded as white, even without directly engaging them. 
Through sharing my own observations and the experiences of the gardeners I interviewed, I aim to demonstrate the whiteness of many of Portland's community gardens and some of the ways whiteness impacts black community gardeners.

\subsection{Observations of Whiteness}

As suggested in previous research (Slocum 2007; Guthman 2008; Pilgeram 2012; Yancy 2017), these spaces become coded as white by the bodies that inhabit them and the values, objectives, and strategies they espouse. Scholars have suggested that this is a product and a process of white privilege (Pulido 2000; Kobayashi and Peake 2000), as the large number of white bodies inhabiting these spaces reinforces white privilege, while it is simultaneously a result of the privileged status of many of the white gardeners. The gardens I spent time observing rarely had more than a few gardeners present at once, but it was usually white individuals I would find in the gardens or near them. One stark exception to this was one of the gardens I observed in North Portland which was centered in the middle of a park that was usually bustling with people of color, most of whom were black. However, the only two black gardeners in the garden were a couple who had recently moved the US from Africa. The rest of the gardeners I observed and spoke to in that garden were white, and many of them drove in from outside of the neighborhood. Even in this neighborhood, which had a large and visible African American population, the community garden was a white space.

The three PPR community gardens located in Albina (which I originally imagined would be of great import for this research) were unfortunately not included in the gardens I observed, because they were almost completely populated by white gardeners, with no 
gardeners identifying as black or African American in 2016 (Portland Parks and Recreation 2016). A manager of one of these gardens confirmed that this was also the case in 2017, in a reply to my recruiting email that stated that there were only white gardeners in their garden. Even the few PPR gardens that had larger numbers of people of color often had white managers, which has been a point of contention in previous research on community gardens, in which white leadership has been ill-suited to understand the needs, concerns, and values of the gardeners of color they oversee (Hoover 2013; Passidimo 2014; Bowens 2015). One of the gardeners I interviewed provided an interesting exception to this pattern. That individual, who identified as black, was the manager of his PPR community garden and the majority of the other gardeners were Eastern European. Despite the fact that most of these gardeners did not speak English, this garden appeared just as white as many of the other PPR gardens at first glance. While seemingly trivial, this specific instance demonstrates the malleability of whiteness (Delgado and Stefancic 1997, 2017; Bonilla-Silva 2003), which allows certain groups to 'pass' or be perceived as white (Pulido 2000) and possibly reap some of the benefits associated with white privilege.

Another way in which I was able to observe the whiteness of the gardens was through my interactions with other white community gardeners. Multiple white individuals demonstrated their white privilege by reaching out to me directly with their criticisms of my research. There were concerns about the imagery used on my flyers (a green fist above farm rows: the logo for the Black Farmers and Urban Gardens Conference) and the “divisive nature” of my project. Multiple white individuals claimed that it was unnecessary, or that I would get a biased (and somehow less valuable) 
perspective by only including black individuals and that I should take a more neutral (read: colorblind) approach. While these views may not have been harbored with malicious intent, their embodiment by garden participants and leaders perpetuates ongoing structural racism and defends the white privilege embedded into these spaces. The officiousness expressed by these individuals further highlights the white privilege at play, which makes whites feel entitled to have control over the spaces they inhabit. These unsolicited criticisms also demonstrate how these beliefs are built into white normativity and the white gaze in way that yields the whiteness of these spaces as invisible to most white gardeners, as well as to garden management and staff (though some may obviously be more cognizant than others).

While the current director and staff of PPR's community garden program are making efforts to make the community gardens more equitable (which are discussed in more detail below), the underlying color-blindness (Gooding-Williams and Mills 2014; Bonilla-Silva 2015) of the PPR community garden system may be reinforcing the whiteness of Portland's gardens. Color-blindness, as described in the literature review, is an ideology that ignores race-based differences in experiences and outcomes between whites and people of color, resulting in "raceless explanations for all sorts of race-related affairs” (Bonilla-Silva 2015:1364). This ideology is coupled, by the majority of white Americans, with the belief that racial justice has been fully achieved in the US, and that therefore no further efforts are needed to address racial disparities (Gooding-Williams and Mills 2014). These views have been embedded in the PPR system and broader social institutions in society in a way that makes these efforts quite challenging. While these efforts can have some impact on the overall dynamics of the gardens, individual 
perspectives are less easily influenced by efforts at inclusion or even policy changes within PPR's community garden program.

One of the individuals who contacted me about their concern over my research was the former coordinator of the community garden program, who played a pivotal role in the proliferation of community gardens in Portland for over two decades. She informed me that PPR's community garden program "adheres to policies of inclusion, fairness and understanding of long time inequities in the cultural mix," but was clear that the gardens were not political spaces to be used for the pursuit of justice (Pohl 2017). I found an interview with this same individual as part of Portland State University's Sustainability History Project, which has been ongoing since 2006. The interview took place in 2009, a couple years before the position was turned over to the current program coordinator. In the interview, she suggested that "the gardens belong to the people," who should be involved in the process of developing and creating gardens. However, when discussing those who might be opposed to community gardens she also said:

There is a minority of people who might be nay-sayers, that don't like the looks of a community garden or don't get how it works or the beauty of it or the magic of it, and their loud voices really bother me. I have to just sort of understand that they just haven't been affected by and they don't see the value, but I wish they would. (Pelling 2009)

While the previous coordinator may not have been explicitly referencing black individuals with this comment, her unwillingness to consider marginal perspectives and her solipsism regarding the value of a community gardens are exemplars of the white gaze, which often leads white individuals to feel that they should 'show the way' for people of color (Slocum 2007; Guthman 2008; Hoover 2013; Passidimo 2014). While 
individuals who hold these beliefs may not have deliberate intentions of upholding racism, the persistence of this way of thinking perpetuates the structures which do so.

As mentioned above, PPR is aware that there is some concern over the racially equitable distribution of its gardens and their benefits, a conclusion possibly drawn from the awareness of this and other research, concerns from the community, or a combination of both. At some point between the February of 2017 and February of 2018 the Community Garden Program added the following statement to the homepage of their website:

Portland Community Gardens is committed to the overall Citywide vision that race will have no detrimental effect on people of color, refugee and immigrant communities in accessing our community gardens, or from the benefit of our services. We recognize that achieving racial equity will take time, with dedicated leadership and commitment by managers and staff. We acknowledge, understand and encourage celebration of the differences that surround us. Equity, inclusion and diversity are vital to Portland Parks \& Recreation’s ideals and values. (Portland Community Garden Program 2017; 2018)

Additionally, PPR was collecting race and ethnicity data from individuals who accessed its services in order to track and improve these outcomes. After two years though, they halted the collection of this information for any of their programs, partly in reaction to the heightened racial climate and community concerns that this information would be used against them (Niemi 2018).

The community garden program has been making efforts to address some of the concerns. For example, they conducted interpreted "listening sessions" with several of the largest non-English speaking groups that were currently utilizing the gardens, and then made policy changes to try and make the gardens more accessible to those and other marginalized groups. However, no listening session was held for African American 
gardeners. This was apparently due to the low number of African American individuals currently accessing PPR's community gardens (Niemi 2018). These listening sessions highlighted a number of ways that marginalized groups might be made to feel more welcome in the gardens, including clearer and better regulated plot boundaries and walkways. The community garden program staff moved towards more strictly enforcing the updated rules after the listening sessions took place, in an effort to make the gardens more inclusive for those less represented groups. It was mostly white gardeners who pushed back against this enforcement though, as they had been previously been allowed more freedom in the gardens (Niemi 2018). This is an excellent example of how efforts to move towards a more equitable or just model are often resisted by whites who (whether knowingly or not) aim to retain their privilege. Many of the black gardeners I interviewed also experience white resistance in additional ways, which will be discussed in more detail towards the end of the next section.

\subsection{Experiences of Black Gardeners}

While many of the community gardens (and the community garden system more broadly) can be coded as white through my own observations and experiences, the experiences of the black community gardeners I interviewed most effectively demonstrate the whiteness of these spaces, and the way this whiteness impacts black community gardeners. When discussing the ways they experienced whiteness within community gardens, there was a wide range of responses from very explicit acts of whiteness to more general effects of being in a white space. Several gardeners described that despite appearing subtle, the impacts of whiteness are still detrimental. Henry 
explained that "I don't think that anyone has been over aggressive but the microaggressions, you could feel them just the same, if not even more.” This subtleness contributes to the invisibility of whiteness to most white individuals (Delgado and Stefancic 1997, 2017; Doane 2003) who are the most common perpetrators of racial microaggressions. Other gardeners also described experiencing microaggressions in their gardens, including being treated as unskilled or inferior, having their cultural preferences mocked or minimized, and being treated as a threat or security risk in the garden.

The two most common expressions of whiteness that were generally experienced among the gardeners I interviewed were the normative whiteness of the gardens and the white gaze of the individuals who inhabit them. These two aspects often functioned in concert within the gardens, as previously suggested in the literature. The gardeners I interviewed also experienced whiteness through structural oppression and resistance from white individuals, which are both regularly connected to white privilege. While these experiences were quite common among the African American and black individuals who were born in the US, they were not equally expressed by the few gardeners I interview who had recently moved here from Africa. These four gardeners seemed hesitant to say anything critical or negative about their experiences, and their general attitudes can be best illustrated by Samira's response to my inquiry into any negative experiences she may have had at the garden. Samira claimed that there was not a single negative experience she could think of, stating that "everything was good. Everything was good, good, good. I have nothing bad to say.” 
White normativity

As discussed in the literature review, whiteness is normative in the way it marginalizes the culture of people of color (Delgado and Stefancic 1997, 2017; BonillaSilva 2003; Doane 2003; Yancy 2017). The white gaze reinforces white normativity by viewing other ways of knowing or being as less legitimate, and casting black individuals as less knowledgeable, incapable, or even criminalistic (Du Bois 1995; Omi and Winant 2015; Delgado and Stefancic 2017; Yancy 2017). Zawiya, a plot holder at a PPR garden, pointed out that the white normativity of these spaces was not as much uninviting as it was unappealing to black gardeners (and possibly other gardeners of color):

I wouldn't say they're not inviting. I would say that- I mean this is gonna sound like a pretty harsh rebuke, but people just don't want to be around white people who want the discussion, the produce, the culture to be about white things. It's not that their unwelcoming, it's just that their undesirable.

Normativity also functions to marginalize the culture of black gardeners in white gardens, both through a lack of representation of that culture and through direct acts of minimizing or othering that culture. An example of how this can occur was offered by Zawiya:

In the late fall I plant collard greens and mustard greens for my Thanksgiving meal and I constantly get the question, "Well kale-" This happened to me the other day, that someone said, "oh that's not a part of the Thanksgiving tradition" and I'm like "get out of here with that."

While this comment may not have been made with malicious intent, the invisibility of whiteness masks the way this type of perspective devalues the culture of nonwhite groups and individuals, who may or may not choose to celebrate Thanksgiving with foods that represent their own culture and identity. Thus, the white gaze is regularly experienced in the form of microagressions like these in community gardens. 
Some gardeners who rented plots in PPR gardens experienced the white normativity of the garden through being treated as an outsider or intentionally excluded from the garden's social network. Lisa provided an example of this when she indicated that she felt that she may have been intentionally left out of social gatherings:

They post if there's a potluck or something but I have a sense that people know each other here and they... I don't know if they just are friendly with each other or what? I know some people are part of the same family but it seems like, I know there's an email list or there're emails that go out. They're like, "Oh, you didn't get that email?" I'm like, "no, I didn't get that email."

This type of exclusion contributes to the whiteness and "viscosity" (Slocum and Saldanha 2013; Ramirez 2014) of these spaces, which makes them seem impermeable to people of color. While black individuals may be able to gain access to the physical space of community gardens in Portland, gaining access to the social networks of the mostly white gardeners may prove to be more of a challenge. This yet another way in which white privilege and normativity reinforce the whiteness of these spaces.

Beyond the whiteness of individual garden spaces, Oregon's food system is also racialized through white normativity. Participants who discussed this topic in the interview often noted that this was the result of historical processes, or the racial formation of Portland. Cherise had originally attempted to complete the Beginning Urban Farmers Apprenticeship (BUFA), which is a training program that individuals pay for to learn about urban farming in Oregon. However, part way through the program she decided to drop out after finding that:

The food system here in Oregon is dominated by a lot of white folks. So even though there's other communities that have been doing the work, it's just like for us... well for me, I guess I'll speak for myself. It just wasn't- didn't feel like it was a good fit. You know, it's just the same thing over and over again, whether you go to university or you go to the BUFA program or you know, working at the county, 
you're just in a very white space and kind of those microaggressions and things like that seem to pop up quite a bit.

Cherise also went on to explain that most of the people in the program, in addition to being white, also had access to or ownership of land in which to apply the skills they were learning. This is also a process of Oregon’s racial formation, in which black individuals were systemically prevented from owning property in nearly all parts of the state. While her (white) Mother's side of her family has had possession of agricultural land in Oregon dating back 4 generations, Cherise has been unable to gain access to it.

The white gaze

The other most commonly experienced expression of whiteness that the gardeners I interviewed described experiencing was the white gaze, which is a standpoint or way of looking at the world that is founded in white solipsism and embedded with racist myths, through which non-white individuals and their culture are viewed as less valuable or legitimate (Du Bois 1995; Kobayashi and Peake2000; Omi and Winant 2015; Yancy 2017). The white gaze was experienced in physical form by several gardeners, who expressed some experience of being watched or looked at excessively, or differently than other gardeners. Lisa expressed the feeling that an expectation of being inferior accompanied the experience of being watched by white gardeners:

I haven't quite figured out why yet but they're- they're very curious. Like they observe you a lot, like you're being watched from the second you walk in. I was being watched anyway; I don't know about anyone else's experience, but they watch you. I think there's an assumption that you maybe know less than you do.

Lisa believed that people watched her for security reasons and because they wanted to make sure she knew the rules. These notions of having to follow the rules came up in 
many of the interviews. The combination of normativity and the white gaze often resulted in what felt like an environment of surveillance for black gardeners, especially when combined with the enforcement of rules that gardeners must agree to in order to acquire a plot within the PPR system. Andreka expressed that this feeling was directly related to being black in a white space, both inside and outside of the PPR system:

And one thing I noticed even in the community garden and in this free garden is that I was the only Black people that gardened. We were the only Black family. So with me, it's like you really have to be on your Ps and Qs.

This type of surveillance may be one the bigger barriers for black individuals, especially those who are new or returning to gardening. Cherise explained that she had heard from other black gardeners that the enforcement of the rules was problematic and created a barrier for some black families:

I think the policing of people just trying to grow food is probably a major factor. I have heard from people who feel like whoever's managing those community gardens... they get talked to if they don't garden the way that whoever the organization is perceives that they should do it. Yeah they have specific rules like, oh you got too many weeds. And that's not really a good way to deal with community members where maybe they have different skill sets, where maybe it's there first time gardening, and then it turns them off from even wanting to participate in things like that. And that's maybe one of the reasons why some of the Black families don't want to participate in some of those community gardens.

One of the central tenets of CRT is that racism is an ordinary experience for people of color, and that it is pervasive in our society (Delgado and Stefancic 2017). Even when black garden spaces are established within proximity of white gardens or within white neighborhoods, they still face the effects of white normativity and the accompanying white gaze. Tamica noted that her most negative experiences while working in one of Portland’s black garden spaces were, “folks giving us looks, being in the garden in that area that's just really white.” Her awareness of the white gaze, even in a 
black garden space, is a testament to its pervasiveness. Henry is involved in a black garden space that is very near another white community garden, and his experience demonstrated the way the white gaze and white normativity not only generated tensions between the two groups, but also created a power dynamic that emboldened some white individuals to question their right to even be accessing the land in the first place:

That community garden has been operating for eight years and then all of a sudden they see myself and this rag-tag group of volunteers that don't look like them and don't carry themselves like them, like they know exactly what they're doing and so we've had some instances where people basically questions why we're here; what constitutes us being in the space. Like, "what have you done? What do you know? Are you a Master Gardener?”

This another example of the white gaze being accompanied by expectations of inferiority, as a product of what Case (2012) referred to as "deficit-oriented narratives" and stereotypes that have been embedded into the white gaze over time. Henry described these encounters and these stereotypes as forms of microaggressions. The presence of the white gaze and accompanying microagressions, even in a black garden space, further demonstrates the pervasiveness of race and racism and the racialized nature of community gardening.

\section{Structural oppression}

Portland's racial formation has always involved the oppression of the black community, as is highlighted in Portland's racialized history and the ongoing displacement of the black community. This has left many individuals in the black community with too little time, money, property, and other resources to engage in community gardening. This lack of resources has also created a barrier for the 
development of black garden spaces in Portland. Albert, a PPR community gardener who is the sole black gardener in his garden, noted that he lives in an "upwardly-mobile, upper income neighborhood.” He went on to note that, “except for apartments in the area, it's going to look pretty white and pretty non-immigrant.” Albert recognized that his class status as a well-educated, gainfully employed homeowner allowed him a certain amount of privilege that many black individuals in Portland do not have access to, and that this was part of the reason he felt comfortable in his garden, despite its whiteness.

The most common barrier to developing black garden spaces and engaging in community gardening that were regularly mentioned by the gardeners I interviewed was a lack of resources, including time, money, and land access. This barrier can be understood as a direct result of broader forces of institutional oppression that have historically disadvantaged the black community in Portland, in combination with the ongoing displacement that is a direct result of this oppression. Interviewees regularly made connections between these limited resources and broader systemic racism, which continues to plague Portland's black community. As explained by Donna:

It wasn't even until 2000 that we could- they would let [black individuals] even move outside of the perimeter of North and Northeast Portland unless you were recruited here by a major corporation or you had intermediaries. So the institutional, structural racism that is practiced here in the state prevents us from being able to be, you know, get resources, execute, implement.

While not all gardeners were as explicit in identifying structural racism as a barrier, they were able to identify many of the effects of this form of oppression. Cherise described how the cost of a garden plot along with the other costs of maintaining that plot may be a big enough barrier to keep many black families who are facing economic hardship (often as a result of ongoing oppression) from participating in community gardening: 
I don't know if they cost anything for Portland Parks and Rec but I feel like if you're in survival mode and you're working, you're trying to make ends meet, having a community garden could be the last thing on your list. If you're just trying to get your family stable, I mean even if it is a benefit like I could save money or things like that, you may not be thinking about that.

Other participants echoed this sentiment, including Andreka who focused specifically on homelessness and poverty as issues that the black community is currently facing:

But our dilemma is most of the time we're in crisis and we're just worried about the next day. We're not looking to think about future, weeks down the line, because that's just not where we're at right now. We're looking to survive right now, like "I need a place right now," or "I need food right now." I am not talking about spending 100 dollars to grow some stuff and I may not have time.

As previously discussed, many of Portland's community gardens can be perceived as white simply by being located in a predominantly white neighborhood. This process is no doubt amplified by the recent waves of gentrification that have whitened the few neighborhoods of color that previously existed in Portland. Several interviewees made the direct connection between gentrification and the whiteness of gardens themselves. Sarah, another sole black PPR gardener, noted that all the new apartments and condos would continue to "restrict diversity" in her garden, unless people of color from the outer areas could be somehow incentivized to commute to the inner-city gardens. Discussing the same topic, Henry noted that if a garden is not in an individual's community, they are likely to feel that, "this is not really a place for me,” and Tamica similarly concluded that, “walking around and feeling like an oddball sometimes here doesn't make you really want to stay here.” Jeff shared his thoughts on how the impacts of gentrification might be related to exclusion from gardens located in recently gentrified neighborhoods:

You know since the demographics have shifted so much, you know people are just feeling- you know there were a lot of folks that were feeling less welcome you know, in the neighborhood they grew up in. When they walk in a restaurant 
and people look at them like- they feel like, "why are you here?" kind of thing. And so I don't know if I would extend to gardens or not.

Land or property as a resource was discussed commonly as a barrier, not only in

regards to home ownership, but in regards to establishing black garden spaces. Having

ownership or access to the space in which a community's food is grown and being able to make decisions about how that food is grown is central to the concept of food sovereignty. In connection to discussions of land access, several gardeners expressed a desire to have more than a black community garden, but rather a black community farm where more substantial amounts of food could be grown by and for the black community. Henry shared his desire to move from the space they currently leased to privately owned land, but that this is especially challenging in Portland:

I mean I feel like we actually need access to more land as we're growing because there's community members that are like, hey I'd like to garden or I'd like to farm but, you know, there's only three fourth of an acre that we're really growing on so for us I think it's land access. And the whole thing around like community gardens and leasing property, I mean you're leasing it and so if you look at national programs, you know, there's no guarantee that you'll be able to be on that property forever. So for us, we're really trying to own a land. And so I think that's- that's our biggest need and there's a real problem with land access here.

Henry went on to say that despite his desire to move into a larger and more permanent space that the black community could still benefit from temporary access to land if the city were to make it available. He asked, "Gresham, Portland- they have all these spaces that pretty much sit dormant and if they don't have any immediate need for it, why not give it to the community that is underserved and in need?” These sentiments were echoed by Jay, who emphasized the need for access to good land, "the city of Portland could just give over some of the best land ever, and like there's some amazing land. Like they own so much land. Like, don't give the shittiest land over to someone.” Considering previous 
examples of environmental racism in Portland, such as the relegating of the black community to Vanport City, Jay’s concerns are not unfounded.

Despite the passion of the black community in their pursuit of creating and sustaining black garden spaces, structural racism has definitely impeded the development of black gardens in Portland. According to Donna, "We had I would say 50\% of what we needed, meaning we had the people the passion and the energy but I would say you still need resources, right?” Gentrification has also taken a toll on black garden spaces that have already been established, as the community that could have sustained them was rapidly displaced by white individuals. I visited two of the black garden spaces in the Albina area and found them mostly barren or overgrown with weeds, though periodic work parties did take place at one. However, there is at least one black garden space that is thriving in Portland, and several others that seem to serving people of color particularly well. While the barriers created by institutional oppression will likely persist, so too will the efforts of the black community at creating and sustaining black garden spaces for Portland's black community.

\section{White resistance}

The final way in which whiteness was commonly experienced by the gardeners I interviewed, especially when discussing creating or developing black garden spaces, was resistance from white individuals or organizations. This type of reaction to programs or places exclusively intended to benefit black individuals or other people of color is common amongst white individuals who harbor post-racial beliefs or a colorblind perspective, and therefore think that providing unique opportunities for the black 
community or black individuals is unnecessary or unfair. Cherise had even experienced people calling a training program uniquely for people of color a form of reverse racism, claiming that it was unfair that white individuals could not participate:

I think one thing was when we really blasted it out there that we were gonna come up with this training program, there was a little push back where people felt like it was reverse racism. You know, "why are we creating this program for only people of color?" So we did get some backlash from some people that felt like it's not fair that they can't participate in it.

While some black garden spaces in other cities have been exclusively for black individuals, that is not the general trend in Portland. Henry informed me that there were misconceptions about this at his garden space, but that he tried to make it known that while they do focus on supporting the black community, the space is open to people of any race or nationality. This common misconception often encourages white individuals to resist the establishment of these spaces.

Cherise explained that she was worried that other, mostly white organizations have been receiving grant funding to work with people of color might be critical of their efforts or try to piggyback off of their work in some way. Henry echoed these feelings as well:

I think that there are some organizations that have basically been facilitating these types of things for our community and now that they're seeing we've had people reach out and basically do trainings with them, so that they can continue to do it, rather than just supporting us, rather than just coming and empowering us and saying "hey, you guys are doing really good at this.” So why not for us, by us? You understand what I'm saying? Why can't they just kind of support us to work with our own community?

These perspectives were dually informed by these individuals’ previous lived experiences with whiteness and collective understanding of whiteness, as it functions to maintain white privilege. 
Andreka pointed out how white resistance to black gardens or programs

specifically for black individuals, is hypocritical in a place where so many services and

supports are provided to other marginalized groups:

We can't have a place that solely serves African Americans because we are racist or it's not ethically right. But you can have like the Pacific Islanders that specifically serves Pacific Islanders. Or you can have like IRCO that serviced, you know the refugees that are coming here so that they're tailored to their needs. I mean like I guess they feel like we're American- you know, you guys are Americans you should just be able to boom right on in and used the same services that everyone else does, but that's not so. So I can send an African to IRCO so they can get services that are culturally specific. Where other people are that know their cultural background, that know how they parent, that they know how they eat, they know the foods that they're eating.

Indeed, all four of the African gardeners I interviewed had been introduced to their garden through some outside organization that aimed to improve their well-being by connecting them to culturally relevant foods and activities or simply through access to growing food. When I asked Margaret (with the help of an interpreter) how she found out about the garden she informed me that "I didn't find it by myself. Somebody else got it for me. It's far from where I live but I like it. Because I have a passion for it I don't mind about the distance.” Similarly, Nassim informed me that the offices at the community she lived in helped her gain access to her garden plot:

The office here give me. Yeah, you know one time I come in here. I live close to here, in this area. And then my husband say "I want to garden, you know. Always I do the garden. I need to do garden." Then they say "ok, ok." Then they give me garden.

Rashid also gained access to his garden through the community organization that helped him find his home and job, and Samira was invited to her community garden by a community health worker who visited her at her home. These individuals were also given seeds in addition to the cost of their plots being covered. The garden where both Samira 
and Margaret had plots (garden \#7) was almost entirely populated by non-English

speaking immigrants. However, the leadership was mostly white and the volunteers that worked at this garden were also white, so this garden was the only research site which I chose not to code as a white or black space. This was not the case for any of the African American gardeners I interviewed, who all made independent efforts to make community gardening a part of their life. It may be an important for future research to dig deeper into this phenomenon, and ask why it is that the colorblind ideology seems to weaken in regards to immigrants and refugees, as compared to other people of color who are born and raised in the US.

Finally, Jay lamented that it was not just the creation of physical spaces that have been met with white resistance but also broader, more strategic efforts on behalf of the black community:

We were talking about policy a lot of times too, so we had different people at different tables and we would report out on what we're hearing on different things and we also would kind of set an agenda for black people to advocate on food issues in the city of Portland and Multnomah County. So I mean we were thinking powerfully about how we could influence things but like at the end of the day I felt like all of our recommendations, all of our advice and everything, just got completely shut- like shut up and destroyed. You know like the Multnomah County Food Action Plan got destroyed and erased from history; it's not even in existence anymore.

In this example, Jay does not explicitly state that it was white individuals that resisted these efforts, though his earlier discussion of the City and Multnomah County made it clear that he viewed these as entities led by and consisting of largely whites. Further, Jay's recounting of this experience demonstrates the way policies that support white supremacy are often favored within Portland and Multnomah County, while the efforts of people of color who advocate for food justice are overlooked or ignored. This has 
historically been the case for many institutions in Oregon, as demonstrated by Gibson (2007), Bates et al. (2014), and Burke and Jeffries (2016). In Portland, housing, employment, education, and food policies have all been shaped to benefit white individuals and the expense of black and other people of color. Thus, the white resistance to black garden spaces and garden programs for people of color works largely in defense of white privilege (whether or not that is the intention) and reinforces the institutional oppression and racism that already exists within the city of Portland.

In this chapter I argued that many of Portland's community gardens are coded as white and demonstrated that black community gardeners regularly experience or perceive them as white spaces, which limits or deters their participation in the gardens. While I was unable to visit all of the gardens in Portland, my encounters and observations at several gardens, combined with the perspectives and experiences of the gardeners I interviewed, effectively demonstrate the whiteness of Portland's community gardens. Through the mechanisms of ideological color blindness, white normativity (both within the gardens and at a broader systemic level in the city and state), and the white gaze, these spaces have been experienced and coded as white spaces. Additionally, black community gardeners experienced whiteness in the form of resistance to black garden space. Many of the gardens managed by PPR that I did not spend time at consisted of all or mostly white plot-holders, and were likely as readily coded as white as the majority of the gardens I did observe. There were a few exceptions in East Portland, where a few gardens have a small number of white gardeners, though they are mostly inhabited by Latinx and Asian plot-holders. In some of the gardens managed by other organizations, and in PPR's Woods Community Garden, there are growing numbers of African 
immigrant gardeners as well. While these small signs of progress are hopeful for the overall equity of Portland's community gardening scene, the black community remains marginalized by whiteness within the majority of community gardens in Portland and their efforts at creating black garden spaces continue to be impeded by structural oppression and white resistance. 
5 FINDINGS: BLACK GARDENERS AND BLACK FOOD SPACES

In this chapter, I will argue that the concerns motivating many black community gardeners, including food justice and the desire to resist oppression, made particular garden spaces more appealing. Further, gardeners acknowledged how the presence of other black gardeners, black leadership, and a focus on black identity or black culture were essential in order to pursue these motivations. The gardeners I interviewed also generally implied that these attributes needed to function together to enable black community gardeners to pursue those motivations. Some gardeners individually made the connection between these specific motivations, and the small number of black individuals participating in PPR community gardens. For example, Zawiya suggested that "I think the question of why people are doing it would shine a light on some reasons why there are so few [black individuals] in the public garden system.”

Similarly to the previous chapter, the four African immigrants included in this study were generally an exception to these findings. They made no mention of either gardening to work towards food justice or as an act of resistance, and tended to be motivated by different concerns. These gardeners primarily used gardening as a way to get to know other people or because it was already a regular part of their life before moving to the US. Nassim informed me of the primary reason she had a community garden plot, saying “I meet a lot of people. I see a lot of vegetables grow, so that's nice.” Rashid expressed a similar sentiment, saying, “I find here a lot of people and they work together like friends. I see people happy and making friends. I see people and happy and talking, and talking sometime like it's a story.” Rashid also informed me that he used to 
work on a farm and that everyone grew food back in Chad, where he moved from.

Margaret echoed these thoughts, claiming that for her it was also because she used to be a farmer and enjoyed growing food. Additionally, Margaret shared that she gardened for health reasons, saying:

I have a chronic disease, diabetes, that requires me to do more exercise and this is one way. With the condition I have, the diabetes, I am advised to eat more greens. That will help with my disease so that's why I am doing this.

While their motivations and desires for gardening are no less important than those discussed in the rest of this chapter, it is noteworthy that their motivations were distinctly different from the interviewees who had been born and raised in the US. Black individuals who have only recently moved to the country may be less aware of the issues in the US that motivate the pursuit of food justice, and their experiences with oppression are likely very different from those who are born in the US. These different histories and experiences of oppression likely lead to different forms of resistance, that are beyond the scope of this study.

\subsection{Food Justice}

The concept of food justice or food sovereignty was discussed by several of the gardeners I interviewed. Some interviewees used those terms explicitly, while others discussed individual aspects that are central to food justice or food sovereignty. Specifically, black community gardeners discussed being motivated by desires to empower the black community, achieve greater involvement of community members, and establish more individual and community agency in the provision of food. Some interviewees saw community gardens as a platform for other social justice efforts as well, 
such as Antonio, who expressed a desire for his fellow community gardeners to do work beyond the garden:

I think that's something I'd like to do though, is like have everybody team up again for like, some of those community projects. The city does like a lot of like volunteer projects and stuff like that and I guess that all counts towards community service hours that we all have to do at the garden to stay valid.

Several interviewees also made connections between their motivations and historical Black Power movements, or what Pulido (2016) has referred to as the Black Radical Tradition. For example, Jay connected his desires for a food justice focus to efforts previously put forth by the Black Panthers:

There was no breakfast program ever before the Black Panthers showed the country how it can be done. I always thought food was empowering, and using the same concept that the Black Panthers had, I wanted to use the idea of bringing food together and bringing- growing food and stuff to like empower our community, bring us together. You know hold events, get people organized around this concept of just being empowered together.

The individuals I interviewed also regularly expressed that community gardens could and should be used to provide benefits to the whole community, rather than solely to individual gardeners. Dorothy connected her efforts at community gardening to other ways she pursued food justice, saying, "I volunteer at Sisters of the Road. So I give them my kale because in the summertime, they don't charge people very much, maybe a quarter, and they get a bag of veggies.” While these types in individual acts were common among the gardeners I interviewed, there were also much larger scale ideas shared. Tamica expressed a desire to move from the small community garden she contributed to into a much larger space, in order to provide more benefits to the black community:

Well, not even gardening, but farming you know and so we're just attempting like- "oh that's a beautiful garden," but a farm is what we need. We need to grow 
a massive amount of food for our community because we see our community cannot afford these high end prices for what they say is organic, when it's really not.

Tamica expressed that a larger space would provide a platform for other beneficial programs and offer opportunities for the black community to build and strengthen social networks beyond the community garden as well:

Share the produce, share the opportunities, the volunteer opportunities and building an economic system for young people, getting them on their bikes in the spring time, summer time and doing some delivery just like they used to do newspapers back in the day. But now you're delivering food and making connection with people who look like you.

The model suggested by Tamica is similar to that of other food justice organizations, such as Clean Green in Seattle, Washington, which utilizes a much larger space to grow food for people of color and employs them in the market in which the produce is sold. Growing Power, a black food space in Milwaukee, Wisconsin was discussed at length by Jay, who had a chance to visit the farm and raved about their workshops, partnerships with schools, and store that employs several community members.

Another topic frequently discussed was a desire to more directly involve the community in efforts at creating and sustaining community gardens. Henry pointed out how a lot of the money that has been spent on building community gardens in the past could have been put to more beneficial use by a greater involvement of the communities they serve:

I think it would have been more beneficial to take some of that money and have the community members do a project where they help build. I mean that's what I would like to do cause number one I like building, I like doing that type of thing. So any aspect that happens on our farm, I want to be a part of it. Even if we hired a contractor, I will always be like, "I get to help." Or any of my community members that want to help get to help. We want to be a part of it. If it's laying down concrete or tearing up concrete, if it's building something, we want to be a 
part of it, cause people who don't have that experience it's almost like training. And the whole project should be teaching people in all aspects of it.

Two of the individuals I interviewed contribute to an organization that has acquired a much larger space that allows for community members to grow food in community, and also has developed additional programs for the black community and other communities of color. In addition to this food justice focus, they work towards developing food sovereignty by taking into consideration the cultural needs and desires of the communities they work with, including not just African Americans, but several Latinx and Somali families as well. Further, they aim to give these communities access to the space and control over how it is shaped and operates. One of them informed me that:

Our hope is it- our hope is to, through (organization) and some of the other community programs we're gonna be putting out, is to obtain long-term leases on some spaces and facilitate them by purchasing seed, helping with crop planting, and having some periodic classes and letting people have access to the space without having to contact us, without us having to be there and no one possesses it themselves. People can come harvest, people can come work.

\subsection{Gardening to Resist}

Many of the black gardeners I spoke to gardened as an act of resistance to oppression, negative stereotypes, or historical trauma. Several of them did so in community gardens that were explicitly identified as black garden spaces, which can act as counterspaces (Case 2012) for black gardeners to pursue these motivations. Black garden spaces are regularly occupied by black individuals, managed by black leaders, and emphasize black identity and culture. This provides opportunities for black individuals to resist deficit-oriented stereotypes, historical trauma, and oppression while working towards food justice. As discussed in the literature review, counterspaces are especially 
important in extremely white environments such as Portland, where the constant exposure to whiteness can be a form of oppression in itself. They are also increasingly necessary in places such as Portland, where gentrification has caused the destruction of the black community and spaces that previously served this function. Jay was involved in establishing one of Portland’s black garden spaces several years ago, partially as a form of resistance to the gentrification in the Albina neighborhood. He indicated that in addition to providing food to the community, the garden was created as a place for black individuals and other people of color to gather. Cherise described how gardens can take the place of other counterspaces that have been eliminated in the process of gentrification and displacement:

And it just becomes the community space to be at. I do feel like because a lot of our black community is spread out in all these weird pockets and because there aren't very many spaces anymore where it's the go-to space for the black community, unless it's the church, and yeah it just leaves very little spaces for people to gather and organize at.

Even though they may be outside the scope of this research, it is also important to note that, there is also a wealth of black gardeners who garden at home and use black gardening collectives as a way to build community around gardening. Zawiya shared this information with me, along with her hope that I not misrepresent the black community in Portland:

I think a lot of people garden at home and they feel unwelcome in the [community] gardens. Also, there's a black gardeners collective so a lot of black gardeners are a part of that collective. They don't want to be a part of the public garden system. I hope that in your final thesis you don't just say that there are few African American gardeners, cause there aren't. There are probably more proportionately; they're just not in the community garden system. 
While these collectives may not be a physical space in the same way a garden is, it is clear that they serve similar purposes and also use gardening as a form of resistance to oppression.

In congruence with the literature, the gardeners I interviewed regularly discussed growing food as "a way to heal the trauma associated with forced agricultural labor and to empower a community through reimagined and reclaimed foodways” (Figueroa and Alkon 2017:217). Henry noted that his family began gardening because, “it was therapeutic for us to grow and it was just like second nature.” Other gardeners were more explicit about what it was that they were trying to heal from, focusing on aspects of historical trauma and persisting effects of racism, dating from slavery all the way up to the war on drugs. As suggested in the literature, several gardeners also expressed that this historical trauma often acts as a barrier to gardening, for some black individuals. Mass traumas that were previously inflicted upon the black community in Portland, or more broadly in the US ,can be a barrier even for those who have not lived through those experiences because "traumatic events reverberate throughout the population, creating a universal experience of trauma” (Sotero 2006: 94-95). Andreka, who previously expressed that she participated in community gardening in order to reclaim or regenerate parts of her identity and culture that had been stripped away, pointed out how the legacy of slavery in the US makes some individuals view gardening and growing food as a negative aspect that they would rather not be identified with:

So I just feel like when we were brought over, came over, whatever, everything was stripped. Everything was stripped. So everything that we do was implemented from someone else. I mean I kind of look at it as, you know that's what we had to do. We had to work the fields. We were enslaved and we had to work the fields. And maybe in some people's mind that's not what I'm gonna do. 
Like, "I'm not a slave no more; I don't have to work the fields. I don't have to do that.”

Cherise noted that the lasting impact of white supremacy in the US is often neglected by the local government and white individuals alike, in community gardens and the rest of the city:

There's trauma too when you think about it. Sharecropping, slavery, all kinds of reason that people might have for not wanting to get involved in a gardening project. And you know, to be honest with you, the city and other folks, they're not really trying to go out of their way to make sure black folks feel welcome in garden spaces or any other space.

In addition to the emotional pain associated with historical racism and oppression in the US, Jay recognized that this history also related to racialized structural barriers, such as access to land:

You know that even after all the history of farming in America, of Black people being abused and exploited for their labor and skills in America, you know, a lot of those labor- all of those skills have been lost and a lot of land got lost. The southern farmers had, basically had like a long tradition that goes all the way back to slavery and sharecropping and like, you know all of this struggle to basically acquire and maintain land that was ancestral land of African Americans who either inherited or bought land over time.

Other gardeners pointed out more local and recent history, such as Sarah who noted that, “the history in Oregon of anyone, a person of color, has not been great,” or Donna who proposed a garden memorial, "in the name of the 1200 Black people that have been murdered here since 1980 because of the War on Drugs.”

Several interviewees also expressed the view that people of color more broadly pursue gardening as a therapeutic way to regenerate or connect to their culture in an effort to resist cultural marginalization. Zawiya described another gardener form Lebanon, who grew a culturally-specific allium, as "soothing his home-sickness with gardening," which she believed to be very different from the reasons most white 
individuals community garden. She suggested that these differences might explain some of the disparities and divisions in the gardens, "because they're coming at two really different issues.” Further, Zawiya pointed out that for black gardeners who pursue gardening as a regenerative or therapeutic activity, microagressions and cultural marginalization are types of intrusions that they intentionally avoid by gardening in places other than white community gardens. These experiences are direct outcomes of the white gaze and white normativity in these spaces, which act as additional sources of marginalization for black individuals who may be attempting to resist cultural oppression. Donna elaborated on this idea of how the white gaze negatively impacts black individuals, with her own experiences in gardening, and beyond:

So when that is happening to you on a daily basis you're constantly being interrupted and bombarded and hit by what, thousands of what negative images. And it really takes work- that's extra work. So it's like having two jobs. The first job is I've just got to keep my mind straight because I'm being bombarded. So when I think about things that were hurtful and harmful to me, that would be something that I would want to prevent ever happening again, right.

\subsection{Reflections, Leadership, and Identity}

Finally, many of the gardeners I spoke to expressed a desire to garden in a community setting in order to be with people who are similar to themselves in appearance, as well as in culture, indicating that other black individuals and people of color were an important attribute to them. This is likely due to the fact that the presence of other people of color helps to "decode” spaces as white, even if it does not code them as a black space. Cherise was talking about other gardeners who might try to garden in white gardens when she said, “people have to be able to relate to you. If they're in a space where they don't necessarily see reflections of themselves or feel welcome, they're 
just gonna be like, I'm not gonna go do that.” Several other gardeners expressed similar ideas, with varying explanations as to why they preferred to garden with other black and people of color individuals. Zawiya expressed that this an outcome of not just white garden spaces, but the effect of living in a white city:

Right, so that's a part of it. It's pretty exhausting to talk about- to be black in Portland I think a lot of people are choosing not to put themselves in situations where they're one of few in their relaxation time.

Zawiya went on to explain how, because of this, people of color tend to seek each other out in white garden spaces. She described this phenomenon in her own community garden:

I do look forward to seeing people in the garden who are more diverse. There's a guy who might be North African but he- he might not identify as black but I think he's like Lebanese or Algerian, so I do see him, and there's a Latino family. We are finding- of the 120 plots we find each other in the garden somehow.

Sarah expressed that she wished her garden had more people of color in it, noting that more diversity in her garden would be nice. Dorothy also expressed a similar sentiment, confessing that she really missed seeing the one other black woman who used to have a plot in her community garden. That woman, coincidentally, was Sarah. Likely because the proportion of black individuals in Portland is so small, these kinds of coincidences were not uncommon. On the rare occasions during my observation at white gardens when there were multiple black individuals gardening, they were usually well acquainted with each other. Especially in Portland, where around three quarters of all individuals are white (Census.gov 2018), being able to garden with other black individuals and people of color was very important to many of the individuals I interviewed.

While many gardeners expressed the desire to be around other black gardeners and people of color, there was also several discussions about the importance of black 
leadership in community gardens, or explanations of how the lack of it is unappealing. For example, Cherise noted that in addition to a lack of "reflections” for black gardeners, that "you don't see reflections of yourself helping to manage that space” in white gardens either. Food justice scholars (McCutcheon 2011; Hoover 2013; Passidimo 2014) agree that black leadership is needed in organizations and spaces that intend to benefit black communities and the privileging of white leadership in alternative food networks has been shown to contribute the whiteness of those spaces (Guthman 2008; Pilgeram 2012), so it is no surprise that black leadership is an important attribute for many black community gardeners. When reflecting on the small number of black individuals in PPR community gardens, Jeff suggested that this may be a direct product of a lack of black leadership:

I would look at what's the staffing of the community garden program. What they look like? Do we have African immigrants? Do we have any local Black folks from the neighborhoods? And I think that to me it always comes down to what do your stuff look like and who are the decision makers. Who has power to make decisions about how to do this?

Jeff's recognition of a racialized power differential within Portland's community gardens was not unique. Donna, who helped develop a community garden in NE Portland, noted that she was motivated by the realization that it was not just farmers markets that were all being "run by the dominant" in Portland, but community gardens as well.

Other gardeners suggested that black leadership was needed, not only at the level of individual community gardens and community garden programs, but on a broader level to motivate the participation of the black community in what several gardeners referred to as “a movement” around community food. Jay noted that: 
There's no movement builder around people of color and food in Oregon. There are Latino movements in Oregon; I'm not denying that. But for African Americans, I feel like there's not a movement leader on these issues, and having somebody who's the movement leader, you know, who is a figure head. It just helps raise money and get things going, I feel like, a lot easier.

Jay’s perspectives about Portland contrasted the movement building that he experienced in places such as New York and Milwaukee, where prominent examples of black food spaces are supported by thriving food justice movements. Tamica echoed these sentiments, suggesting that this broader leadership should include the presence of some prominent black community figure:

Sometimes you gotta get a big name to get somebody on board, and that may be what it's gonna take in order to get more African descent people back to nature, back to the land, and back to their tribe.

However, the presence of black leadership alone may not be enough to increase the number of black gardeners in Portland. One individual I interviewed was a garden manager, which demonstrates the possibility for black leadership within white gardens. However, this did not attract any other black individuals or to decode the space as white. Black "reflections" and leadership tend to work together to provide a positive and beneficial experience for black individuals, and it is unlikely that they will have the same effect individually.

The final attribute that was discussed by many gardeners I interviewed was a focus on black identity and culture. As described in the literature, many food justice organizations emphasize racial identity and focus on enhancing, or in some cases restoring this identity as a means of empowering community. As Ramirez pointed out, race can, "either reify existing inequalities or challenge them, depending on how the food space is being produced” (2014:752). An emphasis on black identity is often used to 
“produce” spaces as black garden spaces and welcome black individuals into that space. Many of the gardeners I interviewed described their motivations for gardening, including the explicit intention of reclaiming parts of their black identity that have been lost or stripped away by the forces of oppression. To this end, many black community gardeners grew food that is culturally representative and an expression of their identity, and expressed a desire to grow food in a space where they were not alone in these efforts.

Finney (2014) explored how historical racism and racial stereotypes have influenced black individuals’ connection to the environment in the US, by creating and embedding these false assumptions in the consciousness of both white and black individuals and communities. Antonio discussed the way he viewed community gardening in relation to the black community in Portland, "I don't know a lot of black people that are into gardening, just generally. Like I know like myself, but uh I don’t have any friends that live in Portland that do it.” Antonio suggested that this may be due to gardening being viewed as something that black individuals do not or should not do. Conversely, Andreka explained how for her, gardening and growing food is part of her culture that she is trying to reclaim and pass on to her children:

But these are things that we did all along and we've gotten away from them. And we're trying to bring folks back to it. I did this when I was kid; this is what we're gonna do. This is something I'm gonna pass to my children that's just like water rafting or camping or anything like that. And as I was saying, taking my family camping is like what? Like black folks don't camp? This is not what we do. But yeah, it is what we do! We've been doing it. I mean we've lived off the land.

Andreka's comparison between growing food and camping engages the notion of deficitoriented narratives (Case 2012) and false stereotypes. By passing these activities on to her children, Andreka aimed to actively establish them as part of their identity as black individuals in an effort to resist these types of negative stereotypes. Similarly, Tamica 
stressed the need to emphasize black identity as a way to show younger black individuals that growing food is a source of empowerment and a way to resist oppression, rather than a continuation of previous forms of oppression:

I also have a dedication to it because I want to leave that legacy, a part of that legacy to my generation, to say that it is ok for us to do this work. Let's not consider it as a bad thing, but let's consider it as an empowerment thing, where we have access, you know resources and all of that.

Whether trying to share this idea with black youth, or with other black individuals of the same age, many of the black community gardeners I interviewed were motivated by a desire to express the growing of food as a part of individual and community identity, as a source of empowerment and in order to resist the dominant ideology in Portland and the US. In one particularly insightful portion of our interview, Zawiya shared that she intentionally and regularly shared photos of her community gardening experiences online, as a way to resist the displacement and dispossession that have been the normative experience for many black individuals throughout US history:

I'm posting these pictures it's almost like- gardening for me is almost like quilting was three hundred years ago for my people, people who made quilts and hung them in the windows to help runaway slaves guide their way to freedom. And I feel like these posts are that my people are on this journey beyond physical freedom to a kind of freedom to live the fullness of the American experience. The black American experience is itinerant, right? We were taken by ship and had the sea voyage here and then sold and moved around and, you know you're constantly moving, stripping yourself of family ties and stripping your connection to a particular place. So then when emancipation happens, the largest migration in American history was the migration of slaves and former slaves out of the south in northern urban centers. So it's been a- it's a culture of constant movement and fleeing and being- and the hardest part of that experience is being stripped of connection to place and indigenousness. That's the deepest wound that we have, and I think what I am trying to signal to people is that I'm reclaiming a place. It's not about sustainability and all that shit. It's like me saying I'm free- in fact I'm free enough to not go anywhere, to not be run out of any place, to not be displaced or sold or run away. 
Many of the gardeners I interviewed made it clear that for them gardening was about black identity and black culture more than anything else. It was not only about their own personal black identity, but about making a contribution to the identity of the black community as a whole and creating spaces for the sharing and expression of black culture. In doing so, these gardeners aimed to provide other individuals with motivation and knowledge to make (or remake) community gardening and growing food a central part of their own black identities.

In this chapter I have argued that different concerns motivate the black community gardeners I interviewed than do many white gardeners, which makes certain garden attributes more appealing to black community gardeners based on the way these attributes enable them to pursue those motivations. I demonstrated black gardeners I interviewed were regularly motivated by food justice concerns and the desire to resist oppression, both of which are enabled by the presence of other black gardeners, black leadership, and a focus on black identity and/or black culture. Because black garden spaces are regularly occupied by black individuals, managed by black leaders, and emphasize black identity and culture, they provide opportunities for black individuals to resist oppression while working towards food justice. While black gardeners may still be able to pursue food justice in white gardens, the motivation of resisting oppression may be more difficult to achieve in these spaces. The whiteness of a garden can make this extremely difficult to achieve, as the white gaze and white normativity can create further oppression through marginalization and microagressions. I also demonstrated that black garden spaces act as counterspaces for the black community, which are increasingly 
important as many spaces that previously served this function have been eliminated as a result of gentrification in Portland. 


\section{CONCLUSION}

This research explored the inequitable distribution of benefits associated with community gardens, which has been a recent point of contention in Portland and in the broader literature on urban agriculture and alternative food. This study also highlighted the way these spaces are coded as white, as well as some of the impacts this has on black community gardeners. Additionally, this research has addressed black garden spaces and their benefit to the black community in Portland. Black community gardeners were chosen for the focus of this research due to their perspectives and experiences as outsiders within (Collins 1986) a white alternative food space, and their status as outsiders within an extremely white city. Their perspectives are recognized as unique and vital both through this standpoint and through the framework of Critical Race Theory, which emphasizes the importance of experiential knowledge, as well as the need to challenge the dominant ideology in the US, using counter-narratives provided by people of color (Delgado and Stefancic 2017).

Overall, this research has demonstrated the whiteness of the majority of Portland's community gardens and the impact this has on black individuals. This research has also shown that black garden spaces provide benefits to black individuals that community gardens that are coded as white do not, and in most cases cannot. Many of these benefits are the result of the specific attributes, which (due to the displacement caused by gentrification) were previously available in the black community in Portland. While the black community seeks to create and sustain spaces such as these, they face barriers as a result of structural racism and white resistance. Additionally, limited 
resources as a result of structural racism are likely preventing many black individuals in Portland from participating in community gardening in any space.

This study has contributed to the literature that is critical of the whiteness of alternative food and urban agriculture, by filling an important gap, in which the perspectives of people of color have largely been missing from the conversation. By sharing the experiences of black community gardeners, I aimed to decenter whiteness and instead highlight the ways in which this whiteness is experienced by black individuals, and how these experiences influence their participation in community gardens in Portland. These findings also offer contributions to whiteness studies more broadly, by demonstrating how the concept of whiteness can be used as a theoretical tool to better understand the experiences of people of color, and offer knowledge that counters the dominant ideology in the US. The final contribution of this study is to the CRT movement and larger body of literature associated with Critical Race Theory. By elaborating on the concept of whiteness using a transdisciplinary perspective, this research has demonstrated ways in which whiteness is major contributor to the experiences of racism that are common to people of color. This conclusion proceeds with a discussion of the individual research question posed earlier in this thesis.

Research Question 1: How do black individuals experience community gardens in Portland, Oregon as racialized spaces?

Most of the black gardeners I interviewed viewed community gardens as racialized spaces, with a sort of dichotomy emerging between white community gardens and black garden spaces. However, there was one community garden I visited where 
neither of these labels would obviously apply. Because the recently migrated African gardeners I interview there had little to say about this specific topic, it was impossible to say how they perceived or experienced the racialization of their garden. Overall, gardens are inevitably coded as white in Portland, unless efforts are taken to emphasize the presence, identity, and culture of people of color. This coding can take place outside of the garden, being based solely on perspectives and previous knowledge, and it can also take place experientially within the garden. Some gardens were perceived as white by the individuals I interviewed, despite never having been in that specific garden. Because whiteness is so normative within Portland, this is not a surprising outcome.

Further, Portland's community gardens are regularly coded as white by their relationship to gentrification, a process that has benefitted whites at the expense of black individuals and other PEOPLE OF COLOR in Portland. This racialized process has led to the displacement of large number of black individuals, and this is viewed as a continuation of the legacy of displacement of the black community in Portland. The coding of these gardens as white is also due to their use as a development tool in Portland, and their subsequent association with the Portland Development Commission and other institutional organizations, which have been largely responsible for the destruction of the black community through their historical development efforts.

Research Question 2: How are black gardener's practices and participation in urban agriculture in Portland influenced by racism and whiteness?

Many of the black gardeners I interview had been deterred from participating in specific community gardens, or had left the program as a result of the whiteness of the 
spaces. The whiteness of the gardens was viewed as a barrier to many, and those who overcame this barrier often encountered racist behavior, such as the marginalization of their culture, microagressions, and expectations of inferiority that are embodied by the white gaze (Yancy 2017). Because of this barrier and because of the way it inhibits black gardeners' ability to resist oppression, many black gardeners choose to garden in black garden spaces. Also, because many black community gardeners in Portland are motivated by food justice concerns, they are drawn to these spaces as this is not a regular aspect of most white gardens. While several of the gardeners I interviewed chose to garden in explicitly black gardens as a result of the whiteness of the majority of community gardens in Portland, there were those who did not know about these spaces, or could not access them, and were left with the choice of participating in a white community garden or no community garden at all. Additionally, it was expressed by one gardener that black garden collectives are another alternative to community gardens, which are pursued by black individuals who prefer not to pursue community gardening due to the whiteness of those spaces.

Research Question 3: In what ways do the features of a community garden influence black individuals’ participation in Portland?

This question was modified from its original form, which asked about the historical influences of individuals’ perceptions of the gardens. While this concept was extremely difficult to get at, another interesting topic arose within the interviews and this question was restated to address that topic. Specifically, the black gardeners I interviewed emphasized the importance of gardening with other people of color and black individuals, 
the necessity for black leadership in community gardens, and an emphasis on black identity and culture. These specific features enabled black gardeners to pursue the two most common motivations that were expressed in regards to community gardening, which were food justice or food sovereignty, and the desire to resist oppression. The whiteness of Portland's community gardens and their inherent lack of the three features described above made them undesirable spaces that were unconducive to achieving these motivations. Black garden spaces stand in direct juxtaposition to these spaces by hailing black gardeners and other people of color, with an emphasis on black identity and culture, as well as programs aimed at benefitting the black community and other communities of color.

\subsection{Policy and Action}

The proliferation of black garden spaces, while an obvious benefit to the black community, would also help to alleviate racial disparities in Portland and would most likely lead to an increase in the overall health and well-being of Portlanders. Similarly, these black garden spaces would likely provide many of the indirect benefits associated with the physical presence of community gardens more generally, including decreased crime, increased social interaction, economic opportunities, and more. White individuals or organization which view these spaces as unfair or as a form of 'reverse racism', should be reminded of the brutally unfair and directly racist history for black individuals in Portland, as well as the current forms of institutional racism which continue to haunt and oppress the black community, displacing them from their communities and leaving them in a constant state of distress. 
While there may be little that Portland Parks and Recreation can do to impact the racialization of Oregon's food system or disrupt structural oppression in Portland more broadly, it may be able to make its community garden program more beneficial to the black community and more socially equitable in the process. While it seems an unlikely prospect, due to the intensity of white resistance faced by individuals and organizations who are already working on this front, this project has made it clear that the creation of a black garden spaces by PPR would be the best course of action. These community gardens would need to be managed by black leaders, and their plot-holders would need to be allowed to emphasize their identity and culture however they see fit. While white and other non-black individuals should be allowed some access to these gardens (to the same extent that the public is currently allowed to access PPR community gardens), only allowing black plot-holders would increase the likelihood of these garden functioning as a counterspaces (Case 2012) for the black community. One of the biggest challenges PPR would need to overcome in this process would be selecting a location that is accessible to the heavily dispersed (and still shifting) black community in Portland. While displacement has forced many black individuals and families out the Albina area, designating a garden in this neighborhood as a black garden could also be symbolic gesture towards the black community.

Another way that Portland Parks and Recreation could continue to improve equity in its gardens and in Portland more broadly, would be to include more of a food justice focus in its mission and policies. While some programs are currently in place that work towards this end, such as Produce for People and the scholarship program for low-income gardeners, PPR could make stronger requirements for individual plot holders to share 
their produce with these programs and could recruit a volunteer "community coordinator" for each garden who would be responsible for creating educational and social events within the garden and involving other community members in these events. PPR could also partner with other social justice and food justice organizations in these efforts, who would likely be willing to use the gardens for more community oriented events and activities.

\subsection{Limitations and Future Research:}

As mentioned in the methods section of this study, my race, age, and level of involvement in the research field were all issues that likely limited this research. In addition to the individuals I did interview possibly holding back some of their thoughts because of my identity, there may have also been potential for more effective recruitment by a person of color who was a bit older and more involved in community gardening or urban agriculture. Several black gardeners I engaged chose not to be interviewed when I asked, and this may have also been a factor of the identity of the researcher. Also, as is the case with all qualitative research with a small number of participants, these findings are not generalizable. While the results of this study have theoretical implications that may apply in other cities as well, the specific findings in this study should not be generalized beyond the perceptions of black individuals I interviewed in Portland.

There are numerous opportunities for future research that became apparent during this study. A more in-depth analysis of the history of community gardens would be of great import, as it would likely allow for a more nuanced understanding of the ways community gardens have been historically tied to larger oppressive structures in Portland, 
such as the Portland Development Commission, which spearheaded much of the historical destruction of the black community. Further, this analysis could shed light on the existence of community gardens in Portland, prior to the creation of Portland Parks and Recreation's program, which were much more likely to be grass-roots style community gardens, created by the community with food justice concerns in mind. In particular, the Beech Community Garden’s history would be of great interest, as it had apparently been operating as a community garden in the Albina neighborhood long before PPR installed water spigots, constructed a fence, and began charging individuals for plots.

Additionally, a qualitative analysis of how (if at all) white community gardeners interpret the racialization of community garden spaces in Portland would be extremely informative. This could take the form of additional interviews or perhaps focus groups, though the content of the study would need to be structured in a way that aimed to avoid centering whiteness, as this has been one of the major criticism of the study of whiteness. It became apparent through white reactions to this research that white individuals likely have some strong feeling about the notion of community gardens being identified as racial projects, and this would inform not only the literature on the whiteness of urban agriculture and alternative food, but the broader literature on whiteness studies. In addition, if white gardeners were less able to see the way race influences the dynamics of community gardens, then this would only further validate the use of the Outsider within Epistemology in future research. 


\section{REFERENCES}

Alkon, Allison Hope \& Julian Agyeman. 2011. "The Food Movement as Polyculture.” Pp. 1-20 in Cultivating Food Justice: Race, Class, and Sustainability, edited by A. H. Alkon \& J. Agyeman. Cambridge: The MIT Press.

Alkon, Allison Hope \& Dena Vang. 2016. “The Stockton Farmers Market: Racialization And Sustainable Food Systems.” Food, Culture, and Society 19(2):389-411.

Alkon, Allison Hope and Julie Guthman. 2017. “A New Food Politics.” Pp. 316-323 in The New Food Activism: Opposition, Cooperation, and Collective Action, edited by Alison Hope Alkon and Julie Guthman. Oakland: University of California Press.

Andersen, Margaret L. 2003. "Whitewashing Race: A Critical Perspective on Whiteness.” Pp. 21-34 in White Out: The Continuing Significance of Racism, edited by Ashley W. Doane and Eduardo Bonilla-Silva. New York: Routledge.

Bates, Lisa, Ann Curry-Stevens \& Coalition of Communities of Color. 2014. The African-American Community in Multnomah County: An Unsettling Profile. Portland, OR: Portland State University.

Bonilla-Silva, Eduardo. 2003. “’New Racism,' Color-Blind Racism, and the Future of Whiteness in America.” Pp. 271-284 in in White Out: The Continuing Significance of Racism, edited by Ashley W. Doane and Eduardo Bonilla-Silva. New York: Routledge.

Bonilla-Silva, Eduardo. 2015. "The Structure of Racism in Color-Blind, 'Post-Racial' America.” American Behavioral Scientist 59(11)1358-1376.

Bowens, Natasha. 2015. The Color of Food: Stories of Race, Resilience, and Farming. British Columbia: New Society Publishers.

Brave Heart, Maria Yellow Horse. 2003. “The Historical Trauma Response among Natives and its Relationship with Substance Abuse: A Lakota Illustration.” Journal of Psychoactive Drugs 35(1):7-13.

Bruening, Jennifer E., Ketra L. Armstrong, and Donna L. Pastore. 2005. "Listening to the Voices.” Research Quarterly for Exercise and Sport 76(1):82-100.

City of Portland. 2015. "First N/NE Housing Project Moves Forward.” Retrieved May 24, 2017 (https://www.portlandoregon.gov/phb/article/528919).

Crenshaw, Kimberlé. 1995. Critical Race Theory: The Key Writings that Formed the Movement. New York: The New Press. 
Creswell, John W. \& Dana L. Miller. 2000. “Determining Validity in Qualitative Inquiry.” Theory into Practice 39(3):124-130.

Collins, Patricia H. 1986. "Learning from the Outsider Within: The Sociological Significance of Black Feminist Thought.” Social Problems 33(6): s14-s32.

Collins, Patricia H. 2000. Black Feminist Thought. New York: Routledge.

Daniels, CarolAnn. 2007. "Outsiders-Within: Critical Race Theory, Graduate Education and Barriers to Professionalization.” Journal of Sociology \& Social Welfare 34(1):25-18.

Delgado, Richard and Jean Stefancic. 1997. Critical White Studies: Looking Behind the Mirror. Philadelphia: Temple University Press.

Delgado, Richard and Jean Stefancic. 2017. Critical Race Theory: An Introduction. New York: NYU Press.

Doane, Ashley W. 2003. "Rethinking Whiteness Studies.” Pp. 3-18 in White Out: The Continuing Significance of Racism, edited by Ashley W. Doane and Eduardo Bonilla-Silva. New York: Routledge.

Draper, Carrie, and Darcy Freedman 2010. "Review and Analysis of the Benefits, Purposes, and Motivations Associated with Community Gardening in the United States. Journal of Community Practice 18(4):458-492.

Du Bois, W.E.B. 1995. “The Souls of White Folk.” Pp. 453-465 in W.E.B. Du Bois: A Reader, edited by David L. Lewis. New York: Henry Holt \& Company.

Figueroa, Meleiza and Alison Hope Alkon. 2017. "Cooperative Social Practices, SelfDetermination, and the Struggle for Food Justice in Oakland and Chicago.” Pp. 206-231 in The New Food Activism: Opposition, Cooperation, and Collective Action, edited by A.H. Alkon and J. Guthman. Oakland: University of California Press.

Finny, Carolyn. 2014. Black Face, White Spaces: Reimagining the Relationship of African Americans to the Great Outdoors. Chapel Hill: University of North Carolina Press.

Flores, Glenda M. 2016. "Discovering a Hidden Privilege: Ethnography in Multiracial Organizations as an Outsider Within.” Ethnography 17(2):190-212.

Friends of Portland Community Gardens. 1995. Letter to the Bureau of Housing and Community Development. (Grant Recommendation) Portland, Oregon: Portland Community Gardens Program, Bureau of Parks and Recreation. 
Fullilove, Mindy Thompson. 2001. "Root Shock: The Consequences of African American Dispossession.” Journal of Urban Health: Bulletin of the New York Academy of Medicine 78(1):72-81.

Garcia, Jennifer J., Gilbert. C. Gee, and Malia Jones. 2016. “A Critical Race Theory Analysis of Public Park Features in Latino Immigrant Neighborhoods.” Du Bois Review 13(2): 397-411.

Gibson, Karen J. 2007. "Bleeding Albina: A History of Community Disinvestment, 19402000.” Transforming Anthropology 15(1):3-25.

Gooding-Williams, Robert and Charles W. Mills. 2014. "Race in a 'Postracial' Epoch.” Du Bois Review 11(1):1-8.

Goodling, Erin, Jamaal Green, \& Nathan McClintock. 2015. "Uneven Development of the Sustainable City: Shifting Capital in Portland, Oregon.” Urban Geography 36(4)504-527.

Guthman, Julie. 2008. “'If They Only Knew’: Color Blindness and Universalism in California Alternative Food Institutions.” The Professional Geographer 60(3):387-397.

Harding, Sandra. 1986. The Science Question in Feminism. New York: Cornell University Press.

Hargreaves, Beth. 1996. "Learning from the Outsider Within: Five Women's Discourses within the Culture of the High School Principal.” Paper presented at the Annual Meeting of the American Educational Research Association, April 8-12, New York, NY.

Henson, Zachary and Genevieve Munsey. 2014. "Race, Culture, and Practice: Segregation and Local Food in Birmingham, Alabama. Urban Geography 5(7):998-1019.

Hern, Matt. 2016. What a City Is For: Remaking the Politics of Displacement. Cambridge: MIT Press.

Hoover, Brandon M. 2013. "White Spaces in Black and Latino Places: Urban Agriculture and Food Sovereignty.” Journal of Agriculture, Food Systems, and Community Development 2(4):109-115.

Jarosz, Lucy. 2008. "The City in the Country: Growing Alternative food networks in Metropolitan areas." Journal of Rural Studies 24:231-244. 
Kobayashi, Audrey and Linda Peake. "Racism out of Place: Thoughts on Whiteness and Antiracist Geography in the New Millennium.” Annals of the Association of American Geographers 90(2):392-403.

Kwon, Hyeyoung. 2015. “Intersectionality in Interaction: Immigrant Youth Doing American from an Outsider-Within Position.” Social Problems 62(4):623-641.

Lawson, Laura J. 2005. City Bountiful: A Century of Community Gardening in America. University of California Press: Berkeley, Los Angeles, London.

Lewis, Amanda E. 2003. "Some are More Equal than Others: Lesson on Whiteness from School.” Pp. 159-172 in White Out: the Continuing Significance of Racism edited by Ashley W. Doane and Eduardo Bonilla-Silva. New York: Routledge.

Lubitow, Amy and Thaddeus R. Miller. 2013. “Contesting Sustainability: Bikes, Race, and Politics in Portlandia.” Environmental Justice 6(4):121-126.

Malakoff, D. 1995. “What Good is Community Greening?” Community Greening Review 5:4-11.

McClintock, Nathan. 2014. "Radical, Reformist, and Garden-Variety Neoliberal: Coming to Terms with Urban Agriculture's Contradictions.” Local Environment 19(2):147-171.

McClintock, Nathan, Dillon Mahmoudi, Michael Simpson, Jacinto Pereira Santos. 2016. "Socio-spatial differentiation in the Sustainable City: A Mixed-methods Assessment of Residential Gardens in Metropolitan Portland, Oregon, USA.” Landscape and Urban Planning 148:1-16.

McClintock, Nathan, Christina Miewald \& Eugene McCann. 2018. “The Politics of Urban Agriculture: Sustainability, Governance, and Contestation.” Pp. 361-367 in The Routledge Handbook of Spaces of Urban Politics, edited by A. Jonas, B. Miller, K. Ward \& D. Wilson. London: Routledge.

McCutcheon, Priscilla. 2011. “Community Food Security 'For Us, By Us’: The nation of Islam and the Pan African Orthodox Christian Church.” Pp. 177-196 in Cultivating Food Justice: Race, Class, and Sustainability, edited by A.H. Alkon \& J. Agyeman. Cambridge: The MIT Press.

Mendes, Wendy, Kevin Balmer, Terra Kaethler, \& Amanda Rhoads. 2008. "Using Land Inventories to Plan for Urban Agriculture: Experiences from Portland and Vancouver.” Journal of the American Planning Association 74(4):435-449.

Morrison, Toni. 1992. Playing in the Dark: Whiteness and the Literary Imagination. Cambridge: Harvard University Press. 
Multnomah County. 2017 "MudBone Grown: RokHedz - GroundUp Organics GreenA\&T.” Retrieved May 21, 2017 (https://multco.us/file/60082/download).

Nemore, C. 1998. "Rooted in Community: Community Gardens in New York City.” Urban Agriculture Notes. Retrieved June 22, 2004. (http://www.cityfarmer.org/NYkcomgardens.html).

Niemi, Laura. 2018. Personal communication (telephone). June 15.

Ohmer, Mary L., Pamela Meadowcroft, Kate Freed, and Ericka Lewis. 2009. "Community Gardening and Community Development: Individual, Social, and Community Benefits of a Community Conservation Program.” Journal of Community Practice 17(4):377-399.

Omi and Winant. 2015. Racial Formation in the United States. New York: Routledge.

Passidimo, C. 2014. "Whose Right to Farm the City? Race and Food Justice Activism in Post-Katrina New Orleans.” Agriculture and Human Values 31(3):384-396.

Pelling, Jane. 2009. "Interview with Leslie Pohl-Kosbau, Community Garden Project (audio).” Sustainability History Project. (http://archives.pdx.edu/ds/psu/10880)

Pilgeram, Ryanne. 2012. “Social Sustainability and the White, Nuclear Family: Constructions of Gender, Race, and Class at a Northwest Farmers Market.” Race, Gender, and Class 19(1):37-60.

Pohl, Leslie. 2017. Personal communication (email). September 4.

Portland Bureau of Parks and Recreation. Community Gardener (plot-holder) Demographic Data. Collected in 2016.

Portland Deltas. 2018 “Green Sustainable Buildings.” Retrieved June 25, 2017. (www.portlanddeltas.org/green-sustainable-buildg).

Portland Community Garden Program. 2001. Request to the Community Livability Group of the Interstate Corridor Urban Renewal Area. (Grant Proposal) Portland, Oregon: Portland Community Garden Program, Bureau of Parks and Recreation.

Portland Community Garden Program. 2017. “Community Gardens.” Retrieved Feb. 21, 2017. (https://www.portlandoregon.gov/parks/39846).

Portland Community Garden Program. 2018. “Community Gardens.” Retrieved Feb. 23, 2018. (https://www.portlandoregon.gov/parks/39846). 
Poulsen, Melissa, Kristyna Hulland, Carolyn Gulas, Hieu Pham, Sarah Dalglish, Rebecca Wilkinson and Peter Winch. 2014. "Growing and Urban Oasis: A Qualitative Study of the Perceived Benefits of Community Gardening in Baltimore, Maryland.” Culture, Agriculture, Food and Environment 36(2):69-82.

Pudup, Mary Beth. 2008. "It Takes a Garden: Cultivating Citizen-Subjects in Organized Garden Projects.” Geoforum 39:1228-1240.

Pulido, Laura. 2000. "Rethinking Environmental Racism: White Privilege and Urban Development in Southern California." Annals of the Association of American Geographers 90(1)12-40.

Ramírez, Margaret Marietta. 2014. "The Elusive Inclusive: Black Food Geographies and Racialized Food Spaces.” Antipode 47(3):748-769.

Renn, Aaron M. 2009. “The White City.” New Geography. Retrieved May 25, 2018. (http://www.newgeography.com/content/001110-the-white-city).

Reynolds, Rema and Darquillius Mayweather. 2017. "Recounting Racism, Resistance, and Repression: Examining the Experiences of \#Hashtag Activism of College Students with Critical Race Theory and Counter Narratives” The Journal of Negro Education 86(3):282-304.

Reynolds, Kristin. 2015. "Disparity Despite Diversity: Social Injustice in New York City’s Urban Agricultural System.” Antipode 47(1):240-259.

Reynolds, Kristin and Nevin Cohen. 2016. Beyond the Kale: Urban Agriculture and Social Justice Activism in New York City. Athens, Georgia: University of Georgia Press.

Saldivar-Tanaka, Laura and Marianne E. Krasny. 2004. “Culturing Community Development, Neighborhood Open Space, and Civic Agriculture: The Case of Latino Community Gardens in New York City.” Agriculture and Human Values 21:399-412.

Sbicca, Joshua. 2012. “Growing Food Justice by Planting and Anti-oppression Foundation: Opportunities and Obstacles for a Budding Social Movement. Agriculture and Human Values 29:455-466.

Shinew, Kimberly J., Troy D. Glover, and Diana C. Parry. 2004. “Leisure Spaces as Potential Sites for Interracial Interaction: Community Gardens in Urban Areas.” Journal of Leisure Research 36(3):336-355.

Slocum, Rachel. 2006. "Anti-Racist Practice and the Work of Community Food Organizations.” Antipode 38(2):327-349. 
Slocum, Rachel. 2007. “Whiteness, space and alternative food practice.” Geoforum 38:520-533.

Slocum, Rachel and Arun Saldanha, eds. 2013. Geographies of Race and Food. Burlington: Ashgate.

Solorzano, Daniel, Miguel Ceja, and Tara Yosso. 2000. “Critical Race Theory, Racial Microagressions, and Campus Racial Climate: The Experiences of African American College Students.” The Journal of Negro Education 69(1/2):60-73.

Sotero, Michelle M. 2006. “A Conceptual Model of Historical Trauma: Implications for Public Health Practice and Research.” Journal of Health Disparities Research and Practice 1(1):93-108.

Steinhauer, J. 2002. “Ending a Long Battle, New York lets Housing and Gardens Grow.” New York Times Metropolitan Desk, September 19, section A, p. 1, column 1.

Thomas, David R. 2006. “A General Inductive Approach for Analyzing Qualitative Evaluation Data.” American Journal of Evaluation 27(2): 237-246.

Thrasher, Dory. 2016. "Fumbling for Community in a Brooklyn Community Garden.” Pp. 159-176 in Cities of Farmers: Urban Agriculture Practices and Processes, edited by Julie Dawson and Alfonso Morales. Iowa City: University of Iowa.

Urban League of Portland. 2017 “Urban Harvest Garden.” Retrieved May 25, 2017 (https://ulpdx.org/get-involved/volunteer/urban-harvest-garden/).

Williams, D., H. Neighbors, and J. Jackson. 2003. "Racial/Ethnic Discrimination and Health: Findings from Community Studies.” American Journal of Public Health 93(2):200-208.

Wright, Richard. 1947. Black Boy. Cleveland: World Publishing Company.

Yancy, George. 2017. Black Bodies, White Gazes: The Continuing Significance of Race in America. Lanham, Maryland: Rowman and Littlefield.

Yoder, Janice D. and Patricia Aniakudo. 1997. “' Outsider Within’ the Firehouse: Subordination and Difference in the Social Interactions of African American Women Firefighters.” Gender and Society 11(3):324-341

Zinschlag, Bryan James. 2014. "Cultivating Common Ground? A Case Study of a Community Garden Organization in Northeast Portland, Oregon.” Master’s Thesis, Department of Sociology, Portland State University, Portland. 
APPENDIX A: INTERVIEW GUIDE

1. How long have you lived in Portland?

a. Oregon, United States?

b. Where did you live before?

2. How did you first start gardening?

3. How long have you been a community gardener?

a. At this garden?

b. Other gardens in Portland?

c. Outside of Portland?

4. Why do you participate in community gardening?

a. Social interaction, health, food security?

i. Which of these reasons is most important?

b. Why did you choose this garden?

i. Close to home?

5. How would you describe your garden plot?

a. How do you decided what to grow?

b. Is there a time of day that you prefer to work in your garden? Why?

Now I would like to switch tracks a bit, and ask you some questions about your community garden space, as a whole.

6. How would you describe the community garden as a whole?

a. Do people interact much?

b. How have you been involved in planning at your garden?

7. How would you describe the typical gardener in your garden?

8. How do you interact with other gardeners?

a. The garden manager?

b. Does race factor in?

9. Can you tell me about a positive experience that you have had in the garden?

a. How about a negative experience?

10. What would you change about your community garden if you could?

11. Why do you think it is that there are such a small number of black or African American gardeners in Portland's community gardens?

12. Do you know any other black community gardeners that would be interested in participating in this project? 


\section{APPENDIX B: HUMAN SUBJECTS APPROVAL}

Post Office Box 751

Portland, Oregon 97207-0751

Date: July 12, 2017
503-725-2227 tel

503-725-8170 fax

To: Julius McGee / David Billings, Sociology

From: Lindsey Wilkinson, IRB Chair

Re:

IRB review determination for your protocol \# 174240, entitled: "Whose Garden? Exploring Experiences of Black Community Gardeners in Portland, OR”

Notice of IRB Review and Determination - Initial Review Exempt Review Category 2; as per Title 45 CFR Part 46

In accordance with your request, the PSU Research Integrity office, on behalf of the IRB (Human Subjects Research Review Committee), has reviewed and approved your protocol for compliance with PSU policies and DHHS regulations covering the protection of human subjects. Research Integrity has determined your protocol qualifies for exempt review and is satisfied that your provisions for protecting the rights and welfare of all subjects participating in the research are adequate. Please note the following requirements:

Approval: You are approved to conduct this research study after receipt of this approval letter, and the research must be conducted according to the plans and protocol submitted (approved copy enclosed).

Consent: You must use IRB-approved consent materials with study participants.

Changes to Protocol: Any changes in the proposed study, whether to procedures, survey instruments, consent forms or cover letters, must be outlined and submitted to Research Integrity immediately. The proposed changes cannot be implemented before they have been reviewed and approved by Research Integrity.

Adverse Reactions and/or Unanticipated Problems: If any adverse reactions or unanticipated problems occur as a result of this study, you are required to notify Research Integrity office within 5 days of the event. If the issue is serious, approval may be withdrawn pending an investigation by the IRB.

Completion of Study: Please notify Research Integrity as soon as your research has been completed. Study records, including protocols and signed consent forms for each participant, must be kept by the investigator in a secure location for three years following completion of the study (or per any requirements specified by the project's funding agency).

If you have questions or concerns, please contact the Research Integrity office in Research \& Strategic Partnerships at hsrrc@pdx.edu or call 503-725-2227. 